IZA DP No. 6623

Employer Learning and the "Importance" of Skills

Audrey Light

Andrew McGee

June 2012 


\title{
Employer Learning and the "Importance" of Skills
}

\author{
Audrey Light \\ Ohio State University \\ Andrew McGee \\ Simon Fraser University \\ and IZA
}

\section{Discussion Paper No. 6623 \\ June 2012}

\author{
IZA \\ P.O. Box 7240 \\ 53072 Bonn \\ Germany \\ Phone: +49-228-3894-0 \\ Fax: +49-228-3894-180 \\ E-mail: iza@iza.org
}

\begin{abstract}
Any opinions expressed here are those of the author(s) and not those of IZA. Research published in this series may include views on policy, but the institute itself takes no institutional policy positions.

The Institute for the Study of Labor (IZA) in Bonn is a local and virtual international research center and a place of communication between science, politics and business. IZA is an independent nonprofit organization supported by Deutsche Post Foundation. The center is associated with the University of Bonn and offers a stimulating research environment through its international network, workshops and conferences, data service, project support, research visits and doctoral program. IZA engages in (i) original and internationally competitive research in all fields of labor economics, (ii) development of policy concepts, and (iii) dissemination of research results and concepts to the interested public.
\end{abstract}

IZA Discussion Papers often represent preliminary work and are circulated to encourage discussion. Citation of such a paper should account for its provisional character. A revised version may be available directly from the author. 


\section{ABSTRACT}

\section{Employer Learning and the "Importance" of Skills}

We ask whether the role of employer learning in the wage-setting process depends on skill type and skill importance to productivity. Combining data from the NLSY79 with O*NET data, we use Armed Services Vocational Aptitude Battery scores to measure seven distinct types of pre-market skills that employers cannot readily observe, and O*NET importance scores to measure the importance of each skill for the worker's current three-digit occupation. Before bringing importance measures into the analysis, we find evidence of employer learning for each skill type, for college and high school graduates, and for blue and white collar workers. Moreover, we find that the extent of employer learning - which we demonstrate to be directly identified by magnitudes of parameter estimates after simple manipulation of the data - does not vary significantly across skill type or worker type. Once we allow parameters identifying employer learning and screening to vary by skill importance, we find evidence of distinct tradeoffs between learning and screening, and considerable heterogeneity across skill type and skill importance. For some skills, increased importance leads to more screening and less learning; for others, the opposite is true. Our evidence points to heterogeneity in the degree of employer learning that is masked by disaggregation based on schooling attainment or broad occupational categories.

JEL Classification: J31, D83

Keywords: employer learning

Corresponding author:

Andrew McGee

Department of Economics

Simon Fraser University

8888 University Drive

Burnaby, BC V5A 156

Canada

E-mail: amcgee@sfu.ca 


\section{Introduction}

The term "employer learning” is typically associated with a class of empirically testable models in which employers learn the productivity of workers over time. In these models, employers are assumed to use schooling attainment and other readily-observed signals to predict productivity and set wages at the start of the career; as workers' careers evolve, true productivity is revealed and the role of schooling in the wage-setting process declines. Building on the work of Spence (1979) and others, Farber and Gibbons (1996) and Altonji and Pierret (2001) were the first to demonstrate that the relationship between a test score and wages is expected to increase with experience in the face of employer learning-where the test score can, in principle, be any measure that is correlated with pre-market productivity but unobserved by employers. Variants of this test have been used by Lange (2007) to assess the speed of employer learning, by Pinkston (2009) and Schönberg (2007) to study asymmetric employer learning, and by Arcidiacono et al. (2010), Bauer and Haisken-DeNew (2001) and Mansour (2012) to investigate differences in employer learning across schooling levels, occupational type (blue versus white collar) and initial occupations, respectively.

In the current study, we ask whether the role of employer learning in the wage-setting process depends on the type of skill potentially being learned over time as well as the skill's importance, by which we mean its occupation-specific contribution to productivity. Basic language skills might be readily signaled to potential employers via the job interview process or their strong relationship with schooling attainment, while other skills such as "coding speed” (the ability to find patterns of numbers quickly and accurately) might only be revealed over time in the absence of job applicant testing. Moreover, the extent to which employers learn about pre-market skill over time-and, conversely, employers' ability to screen for pre-market skill ex ante-is likely to hinge on the skill's importance to the work being performed. If the ability to solve arithmetic problems is irrelevant to the work performed by dancers and bulldozer operators, for example, then the true productivity their employers learn over time should be uncorrelated with a measure of arithmetic skill. Stated differently, the relationship between arithmetic test scores and wages should not increase with experience for dancers and bulldozer operators. In reverse situations where a particular skill is essential to job performance, it is unclear whether signaling or learning will dominate the wage-setting process. Given that arithmetic is critical to accountants' job performance, for example, should we expect arithmetic ability to be a key component of what their employers learn over time? Or do employers customize their screening methods to ensure that the most critical skills are accurately assessed ex ante?

To address these questions, we begin by identifying the channels through which skill importance enters a standard employer learning model. Using the omitted variable bias strategy of Altonji and Pierret (2001) we demonstrate that by using the portion of each test score (referred to as $Z^{*}$ ) that is orthogonal to schooling and other regressors, the $Z^{*}$-experience gradient in a log-wage model is expected to depend solely on the test score's correlation with performance signals that 
lead to learning, while the test score's effect on log-wage levels is expected to depend both on skill importance and the extent to which the skill is signaled ex ante. These derivations motivate our empirical strategy: First, we empirically assess the role of employer learning for alternative skills by inserting skill-specific test scores $\left(Z^{*}\right)$ into a log-wage model and comparing the magnitudes of their estimated experience gradients. Second, we allow coefficients for $Z^{*}$ and $Z^{*}$ experience interactions to depend nonlinearly on skill importance (which we measure directly) to determine whether learning and screening depend on the skill's importance to productivity.

We implement these extensions of conventional employer learning tests using data from the 1979 National Longitudinal Survey of Youth (NLSY79) combined with data from the Occupational Information Network (O*NET). To proxy for pre-market skills that are unobserved by employers, we use test scores for seven components of the Armed Services Vocational Aptitude Battery (ASVAB). The use of narrowly-defined test scores distinguishes our approach from the existing literature, where most analysts rely on scores for the Armed Forces Qualifications Test (AFQT) - a composite score based on four ASVAB components that we use individually. ${ }^{1}$ By using several skill-specific test scores, we can determine whether employer learning plays a different role for arithmetic ability, reading ability, coding speed, etc. We further extend the analysis by using O*NET data to construct "importance scores" representing the importance of each skill in the three-digit occupation associated with the current job. These additional variables enable us to determine whether skill-specific screening (a component of the test score coefficient) and employer learning (which determines the coefficient for the test score-experience interaction) are themselves functions of skill importance.

By exploring the extent to which screening and employer learning differ across jobs, we build directly on the work of Arcidiacono et al. (2010), Bauer and Haisken-DeNew (2001) and Mansour (2012). Using NLSY79 data, Arcidiacono et al. (2010) find evidence of employer learning for men with 12 years of schooling, but not for men with 16 years of schooling. Using data from the German Socioeconomic Panel, Bauer and Haisken-DeNew (2001) find evidence of employer learning for men in low-wage, blue-collar jobs, but not for other men. Mansour (2012) also uses NLSY79 data for male workers, and finds that employer learning is positively correlated with life-cycle wage dispersion in the initial two-digit occupation. To interpret their findings, Arcidiacano et al. (2010) and Bauer and Haisken-DeNew (2001) surmise that highlyschooled or higher-skilled workers are able to signal their productivity to employers at the outset of their careers (abrogating the need for employer learning), while Mansour (2012) concludes

\footnotetext{
${ }^{1}$ We also use AFQT scores in our log-wage models for comparison with existing studies. To our knowledge, no prior study reports estimates based on a cognitive test score other than the AFQT, although Pinkston (2006) notes (p. 279, footnote 23) that he used two ASVAB test scores and obtained results that "resembled" his AFQT-based estimates. As alternatives to test scores, analysts have used parental schooling attainment (Altonji and Pierret 2001; Arcidiacono et al. 2010; Pinkston 2006; Bauer and Haisken-DeNew 2001), sibling wages (Altonji and Pierret 2001; Pinkston 2006) or the presence of library cards in the household at age 14 (Farber and Gibbons 1996; Altonji and Pierret 2001).
} 
that the speed of employer learning varies across occupations. Each of these studies makes an important contribution to the literature, but our approach adds two innovations: First, we explicitly examine the tradeoff between employer learning and screening, rather than simply infer that any absence of learning must be due to increased screening. Second, we allow for a richer form of heterogeneity in screening and learning than is permitted with two schooling categories, two occupational categories, or wage dispersion across two-digit occupations. By allowing learning and screening to differ across seven skill types and, for each skill type, across skill-specific importance scores that vary with three-digit occupation, we identify heterogeneity in employer learning that is masked by broader disaggregation of the data.

Prior to bringing importance scores into the analysis, we find evidence of employer learning for all seven skill types. We also find that differences across skill types in the degree of learning are uniformly insignificant, as are differences across “worker type” (12 vs. 16 years of schooling, or blue collar vs. white collar) for most skills; in contrast to Arcidiacano et al. (2010) and Bauer and Haisken-DeNew (2001), this initial evidence points to little heterogeneity across skills or workers in the role of employer learning. Once we incorporate measures of skill importance, our findings change dramatically. We identify distinct tradeoffs between screening and employer learning for most skill types, and we find that the effect of skill importance on screening and learning differs by skill type. For some skills (mathematics knowledge, mechanical comprehension), screening increases and learning decreases in skill importance; for word knowledge the opposite pattern exists, while for numerical operations employer learning (screening) is least (most) pronounced in the middle of the "importance" distribution. These patterns suggest that the role of employer screening in wage determination depends intrinsically on the type of skill being assessed and the nature of the job being performed.

\section{Model}

The employer learning test proposed by Altonji and Pierret (2001) (hereafter referred to as AP) relies on an assessment of expected values of estimators in the log-wage model that we, the econometricians, estimate. The econometrician's model is misspecified because (a) we necessarily exclude factors that employers use to set wages, but that are unavailable in our data; and $(b)$ for the purpose of studying employer learning, we intentionally include in the model measures such as test scores that we observe but employers do not. In II.A, we overview the AP model, derive the relevant omitted variable bias, and highlight key aspects of AP's test for employer learning. In II.B we turn to the primary goal of this section, which is to demonstrate how AP's test can be extended to assess the role of employer learning for a range of alternative test scores (i.e., skill measures that we observe but employers do not) that differ across jobs in their productivity-enhancing "importance." In II.C, we consider how departures from the model's key assumptions affect our ability to identify the role of skill importance in employer learning. 


\section{A. The Altonji and Pierret (AP) Employer Learning Model}

\section{A.1. Productivity}

Following AP, we decompose the true log-productivity of worker $i$ at time $t\left(y_{i t}\right)$ into its components:

$$
y_{i t}=r S_{i}+\alpha_{1} q_{i}+\lambda^{z} Z_{i}+N_{i}+H\left(X_{i t}\right)
$$

where $S_{i}$ represents time-constant factors such as schooling attainment that are observed ex ante (at the time of labor market entry) by employers and are also observed by the econometrician; $q_{i}$ represents time-constant factors such as references that are observed ex ante by employers, but are unobserved by the econometrician; $Z_{i}$ are time-constant factors such as test scores that the econometrician observes but employers do not; $N_{i}$ are time-constant factors that neither party observes; and $H\left(X_{i t}\right)$ are time-varying factors such as work experience that both parties observe over time. In a departure from AP, we explicitly define $\lambda^{z}$ as the importance of the unidimensional, pre-market skill represented by $Z_{i} \cdot{ }^{2}$ While $Z_{i}$ can be any correlate of productivity that employers do not observe, once we use a specific test score (arithmetic reasoning, coding speed, etc.) as its empirical representation, we are considering that skill's importance to productivity as well as employer learning with respect to that specific skill. ${ }^{3}$

Employers form prior expectations of factors they cannot observe $\left(Z_{i}\right.$ and $\left.N_{i}\right)$ on the basis of factors they can observe $\left(S_{i}\right.$ and $\left.q_{i}\right)$ :

$$
\begin{aligned}
& z_{i}=E\left(Z_{i} \mid S_{i}, q_{i}\right)+v_{i}=\gamma_{1} q_{i}+\gamma_{2} S_{i}+v_{i} \\
& \eta_{i}=E\left(N_{i} \mid S_{i}, q_{i}\right)+e_{i}=\alpha_{2} S_{i}+e_{i}
\end{aligned}
$$

After incorporating these observed signals, at $t=0$ employers believe productivity to be:

$$
E\left(y_{i 0} \mid S_{i}, q_{i}\right)=\left(r+\lambda^{z} \gamma_{2}+\alpha_{2}\right) S_{i}+\left(\lambda^{z} \gamma_{1}+\alpha_{1}\right) q_{i}+H\left(X_{i 0}\right)
$$

where $\lambda^{z} v_{i}+e_{i}$ is the initial error in the employers' assessment of productivity.

Over time, employers receive new information about productivity in the form of a performance history $\left(D_{i t}\right)$ that they use to update their expectations about $Z_{i}$ and $N_{i}$. With this new information in hand, employers' beliefs about productivity at time $t$ are:

$$
E\left(y_{i t} \mid S_{i}, q_{i}, D_{i t}\right)=\left(r+\lambda^{z} \gamma_{2}+\alpha_{2}\right) S_{i}+\left(\lambda^{z} \gamma_{1}+\alpha_{1}\right) q_{i}+H\left(X_{i t}\right)+E\left(\lambda^{z} v_{i}+e_{i} \mid D_{i t}\right) .
$$

\section{A.2. Wages and Omitted Variable Bias}

Given AP's assumption (used throughout the employer learning literature) that workers' logwages equal their log-productivity, we obtain the log-wage equation used by employers directly from 2. In a departure from AP's notation, we write the log-wage equation as:

$$
w_{i t}=\beta_{1} S_{i}+\beta_{2} q_{i}+g_{i t}+\zeta_{i t}
$$

\footnotetext{
${ }^{2}$ Equation 1 imposes the restriction that $\lambda^{z}$ is uniform across employers and occupations; we discuss the implications of relaxing this restriction in II.C.

${ }^{3}$ In section III.B, we point to correlations among our seven test scores to argue that with two notable exceptions (paragraph comprehension and word knowledge; arithmetic reasoning and mathematics knowledge) the test scores appear to measure distinct skills.
} 
where $\beta_{1}=r+\lambda^{z} \gamma_{2}+\alpha_{2}, \beta_{2}=\lambda^{z} \gamma_{1}+\alpha_{1}, g_{i t}=E\left(\lambda^{z} v_{i}+e_{i} \mid D_{i t}\right)$, and $H\left(X_{i t}\right)$ is omitted for simplicity. The econometrician cannot estimate (3) because $q_{i}$ and $g_{i}$ are unobserved. Instead, we use productivity components for which data are available to estimate

$$
w_{i t}=b_{1} S_{i}+b_{3} Z_{i}+\epsilon_{i t} .
$$

AP's test of employer learning is based on an assessment of the expected values of estimators obtained with "misspecified" equation 4. Ignoring work experience and other variables included in the econometrician's log-wage model (which we consider in II.C), these expected values are:

$$
\begin{gathered}
E\left(b_{1}\right)=\beta_{1}+\beta_{2} \delta_{q s}+\theta_{t} \delta_{v s}=\beta_{1}+\beta_{2} \frac{S_{z z} S_{s q}-S_{z s} S_{z q}}{S_{S S} S_{z z}-S_{z s}^{2}}-\frac{S_{z s} S_{z g}}{S_{s S} S_{z z}-S_{z s}^{2}} \\
E\left(b_{3}\right)=\beta_{2} \delta_{q z}+\theta_{t} \delta_{v z}=\beta_{2} \frac{S_{s S} S_{z q}-S_{z S} S_{s q}}{S_{s s} S_{z z}-S_{z s}^{2}}+\frac{S_{S s} S_{z g}}{S_{s S} S_{z z}-S_{z s}^{2}} .
\end{gathered}
$$

The $\delta s$ in 5a-b are from auxiliary regressions $q_{i}=\delta_{q s} S_{i}+\delta_{q z} Z_{i}$ and $v_{i}=\delta_{v s} S_{i}+\delta_{v z} Z_{i}$, where $v_{i}$ is now "shorthand" for initial error $\lambda^{z} v_{i}+e_{i}, \theta_{t}=\frac{S_{z g}}{S_{z v}}, S_{z g}=\sum\left(Z_{i}-\bar{Z}\right)\left(g_{i t}-\bar{g}\right)$, and $S_{z v}=\sum\left(Z_{i}-\bar{Z}\right)\left(v_{i}-\bar{v}\right)$; the remaining variance and covariance terms in 5a-b are defined similarly $\left(S_{z z}=\sum\left(Z_{i}-\bar{Z}\right)^{2}\right.$, etc. $)$.

In $5 \mathrm{a}$, the first term $\left(\beta_{1}\right)$ represents the true effect (per equation 3 ) of $S_{i}$ on log-wages, the second term represents the time-constant component of the omitted variable bias, and the third term (by virtue of its dependence on $g_{i t}$ ) is the time-varying component of the omitted variable bias. Similarly, in $5 \mathrm{~b}$-where there is no true effect because $Z_{i}$ is not used by employers in the wage-generating process - the first (second) component of the omitted variable bias is constant (varying) over time.

\section{A.3 AP's Test of Employer Learning}

AP's primary test of employer learning amounts to assessing the sign of the time-varying components of the omitted variable biases in 5a-b. Given the relatively innocuous assumptions that $S_{z v}>0, S_{z s}>0$, and $Z_{i}$ and $S_{i}$ are scalars, it is apparent that (a) the time-varying component of $5 \mathrm{a}$ (the third term in the expression) is negative and (b) the time-varying component of $5 \mathrm{~b}$ (the second term) is positive. Stated differently, the expected value of the estimated $S_{i}$ coefficient in the econometrician's log-wage model declines over time, while the expected value of the estimated $Z_{i}$ coefficient increases over time.

AP and subsequent contributors to the literature operationalize this test by modifying specification 4 as follows:

$$
w_{i t}=b_{1} S_{i}+b_{3} Z_{i}+b_{4} S_{i} \cdot X_{i t}+b_{5} Z_{i} \cdot X_{i t}+\epsilon_{i t},
$$

where $S_{i}$ is typically a self-reported measure of "highest grade completed," $Z_{i}$ is often a test score, and $X_{i t}$ is a measure of cumulative labor market experience. A positive estimator for $b_{5}$ is evidence in support of employer learning; a negative estimator for $b_{4}$ is evidence that employers use schooling to statistically discriminate regarding the unobserved skill, $Z_{i}$. 


\section{B. Assessing Employer Learning for Different Skills and Skill Importance B.1 Skill Type}

Our first goal is to estimate specification 6 using alternative, skill-specific test scores to represent $Z_{i}$, and use the set of estimators for $b_{3}$ and $b_{5}$ to compare signaling and employer learning across skills. To do so, we must assess the magnitudes of the time-varying components of the omitted variable biases in 5a-b. This constitutes a departure from AP, who did not seek to make comparisons across alternative test scores; as discussed in II.A.3, AP's objective simply required that they sign each time-varying component.

Inspection of 5a-b reveals that the time-varying components (i.e., the right-most terms) depend on $S_{z g}$, which represents the covariance between the test score used in estimation $\left(Z_{i}\right)$ and the employer's updated information about productivity $\left(g_{i t}=E\left(\lambda v_{i}+e_{i} \mid D_{i t}\right)\right)$, as well as $S_{z s}, S_{z z}$, $S_{s s}$. While $S_{z g}$ is a direct measure of employer learning, two of the remaining three terms (the covariance between $Z$ and $S$ and the variance of $Z$ ) also vary across test scores and can confound our ability to interpret $\hat{b}_{5}$ for each test score as a skill-specific indication of employer learning.

To address this issue, we follow Farber and Gibbons (1996) by constructing skill-specific test scores that are orthogonal to schooling. We define $Z_{i}^{*}$ as the residual from a regression of $Z_{i}$ on $S_{i}$ and a vector of other characteristics $\left(R_{i}\right):^{4}$

$$
Z_{i}^{*}=Z_{i}-E^{*}\left(Z_{i} \mid S_{i}, R_{i}\right) .
$$

If we normalize each $Z_{i}^{*}$ to have unit-variance $\left(S_{z z}=1\right)$ and replace $Z_{i}$ with this standardized residual in specification 6 , then the time-varying components of the omitted variable biases in 5a-b reduce to:

$$
B_{1 t}=-\frac{S_{z S} S_{z g}}{S_{S S} S_{z z}-S_{z S}^{2}}=0 \text { and } B_{3 t}=\frac{S_{S S} S_{z g}}{S_{S S} S_{z z}-S_{z S}^{2}}=S_{z g} .
$$

The simplified expression for $B_{3 t}$ indicates that by using standardized, residual test scores, the $Z$ $X$ slope in specification 6 is determined entirely by employer learning. ${ }^{5}$ This suggests that if we use a $Z_{i}^{*}$ about which the performance history is particularly revealing, then we can expect the coefficient for $Z_{i}^{*} \cdot X_{i t}$ identified by 6 to be particularly large. To summarize our first extension of AP's test: we use alternative measures of $Z_{i}^{*}$ in specification 6 and compare the magnitudes of $\hat{b}_{5}$ to judge which skills employers learn more about. ${ }^{6}$

\footnotetext{
${ }^{4}$ We defer discussion of the "other" characteristics $\left(R_{i}\right)$ to II.C and III.B.

${ }^{5} S_{z g}$ in 8 now refers to the covariance between $Z_{i}^{*}$ (not $Z_{i}$ ) and productivity signals. We use $Z_{i}^{*}$ (standardized, residual test scores) throughout our empirical analysis, but in the remainder of this section we often leave implicit that $Z_{i}$ is, in practice, transformed into $Z_{i}^{*}$.

${ }^{6}$ The expression for $B_{1 t}$ in 8 indicates that once we replace $Z_{i}$ with $Z_{i}^{*}$, we should expect $\hat{b}_{4}$ in specification 6 to be zero because $S_{i}$ does not serve as a signal for the portion of $Z_{i}$ that is orthogonal to schooling. This testable hypothesis originates with Farber and Gibbons (1996) who, in contrast to AP, also used $Z_{i}^{*}$ rather than $Z_{i}$ as a regressor.
} 
The time-constant components of the omitted variable biases in 5a-b are also of interest, given that these terms represent the extent to which $Z_{i}$ is tied to initial wages via signaling. After replacing $Z_{i}$ by $Z_{i}^{*}$ and standardizing, the time-constant components of the omitted variable biases are given by:

$$
B_{10}=\beta_{2} \frac{S_{z z} S_{s q}-S_{z S} S_{z q}}{S_{s S} S_{z z}-S_{z s}^{2}}=\beta_{2} \frac{S_{s q}}{S_{s S}} \text { and } B_{30}=\beta_{2} \frac{S_{s S} S_{z q}-S_{z s} S_{s q}}{S_{s S} S_{z z}-S_{z s}^{2}}=\beta_{2} S_{z q} .
$$

The expression for $B_{30}$ reveals that the time-invariant relationship between $Z_{i}^{*}$ and log-wages increases in $S_{z q}$, the covariance between the skill and productivity signals $(q)$ observed ex ante by the employer but not the econometrician. All else equal, we expect the estimated coefficient for $Z_{i}^{*}$ in specification 6 to be larger for test scores that are relatively easy to assess ex ante via their correlation with signals other than $S_{i}$; unsurprisingly, the skills measured by such test scores would contribute relatively more to initial wages under these circumstances.

However, we cannot apply this argument to our interpretation of $\hat{b}_{3}$ because "all else” is not held constant as we substitute alternative test scores into the regression. In particular, $B_{30}$ (as well as $B_{10}$ ) depends on $\beta_{2}$ which, in turn, depends on structural parameters $\alpha_{1}, \lambda^{z}$, and $\gamma_{1}$. As discussed in II.A.1, $\lambda^{z}$ reflects the "importance" of $Z_{i}$ to productivity. If $\hat{b}_{3}$ changes magnitude as we substitute alternative test scores into specification 6 , we cannot determine whether the change reflects cross-skill differences in signaling $\left(S_{z q}\right)$ or skill importance $\left(\lambda^{z}\right)$. As explained below, we can make this distinction in select circumstances by using data on skill importance. More generally, we simply view the combined effect of $S_{z q}$ and $\lambda^{z}$ (what employers learn via screening combined with how they weight that ex ante information) as the screening effect.

\section{B.2 Skill Importance}

Building on the preceding discussion, we consider three avenues through which skill importance can affect the wage-generating process and, therefore, the omitted variable biases shown in 8-9. First, importance affects $B_{30}$ directly through $\beta_{2}$, which is a function of $\lambda^{z}$, so the estimated coefficient for $Z_{i}^{*}\left(\hat{b}_{3}\right)$ in 6 will depend in part on the skill's importance. Second, importance affects $B_{30}$ indirectly if employers' ability to screen for a particular skill is itself a function of importance-that is, if $S_{z q}$ depends on $\lambda^{z}$, presumably because employers screen more intensively (or efficiently) for those pre-market skills that matter the most. For example, dancing skill is critical for a dancer while arithmetic skill is not, so dancers' employers are likely to hold dance auditions (a component of $q$ ) prior to hiring but not administer an arithmetic test. Third, importance affects $B_{3 t}$ directly because the covariance $\left(S_{z g}\right)$ between skill and time-varying productivity signals that give rise to learning-i.e., the covariance between $Z_{i}^{*}$ and $g_{i t}=$ $E\left(\lambda^{z} v_{i}+e_{i} \mid D_{i t}\right)$-depends on skill importance, and not just the skill itself. This implies that the estimated coefficient for $Z_{i}^{*} \cdot X_{i t}\left(\hat{b}_{5}\right)$ in specification 6 will depend on skill importance. ${ }^{7}$

\footnotetext{
${ }^{7}$ Altonji (2005) proposes a model in which the rate at which employers learn is directly related to the overall level of skill importance in an occupation. He does not pursue this extension empirically.
} 
To assess the role of skill importance on learning and screening, we augment specification 6 to allow $b_{3}$ and $b_{5}$ to depend nonlinearly on skill importance:

$$
w_{i t}=a_{1} S_{i}+\sum_{j=1}^{3} d_{i j} a_{3 j} Z_{i}+a_{4} S_{i} \cdot X_{i t}+\sum_{j=1}^{3} d_{i j} a_{5 j} Z_{i} \cdot X_{i t}+a_{6} I S_{i t}^{Z}+\epsilon_{i t},
$$

where $I S_{i t}^{Z}$ is an "importance score" representing the importance of the skill measured by test score $Z_{i}^{*}$ for the occupation held by worker $i$ at time $t$; we view $I S_{i t}^{Z}$ as a direct measure of $\lambda^{z}$. The three $d_{i j}$ are dummy variables indicating whether $I S_{i t}^{z}$ falls in region $j$ (quartile 1 , quartiles $2-3$, or quartile 4) of the empirical distribution of importance scores. After extensive experimentation, we determined that this specification — which extends 6 by identifying separate coefficients for $Z_{i}^{*}$ and $Z_{i}^{*} \cdot X_{i t}$ depending on whether the skill measured by $Z_{i}^{*}$ is of "high," "low" or "medium" importance-adequately captures the patterns in the data.

Because the time-varying component of the relationship between $Z_{i}^{*}$ and $w_{i t}\left(b_{5}\right.$ in specification 6 and $a_{5 j}$ in 10) is a function only of $S_{z g}$, we can interpret any $I S_{i t}^{Z}$-pattern in the $Z_{i}^{*}$ - $X_{i t}$ slope as representing the effect of skill importance on employer learning. In principle, learning can increase, decrease, or change non-monotonically with importance. Estimates for $a_{3 j}$ are potentially more difficult to interpret because the time-constant component of the relationship between $Z_{i}^{*}$ and $w_{i t}\left(b_{3}\right.$ in specification 6 and $a_{3 j}$ in 10) is a function of both $S_{z q}$ and $\lambda^{z}$. Given that $\lambda^{z}$ tautologically increases in its empirical analog $I S_{i t}^{z}$, a finding that the estimated $Z_{i}^{*}$ coefficient declines in skill importance is unequivocal evidence that screening $\left(S_{z q}\right)$ declines in skill importance. If the estimated $Z_{i}^{*}$ coefficient increases in skill importance, we cannot determine whether $S_{z q}$ increases or decreases in importance. We illustrate this ambiguity by considering the case where $Z_{i}^{*}$ measures arithmetic ability and "increased importance" corresponds to moving from a dance company to an accounting firm. The scenario where $S_{z q}$ increases in importance corresponds to accounting firms screening for arithmetic skill more effectively than dance companies; in addition, accounting firms necessarily put more weight on arithmetic skill in the initial wage-setting process, so a given amount of arithmetic skill translates into higher initial log-wages for accountants than for dancers because both $S_{z q}$ and $\lambda^{z}$ are larger. In the alternative scenario, accounting firms screen less effectively than dance companies for arithmetic skill but place a greater weight $\left(\lambda^{z}\right)$ on whatever arithmetic skill they are able to identify ex ante; a given amount of skill continues to translate into a higher initial log-wage for accountants than for dancers because the smaller $S_{z q}$ is offset by a larger $\lambda^{z}$. We cannot distinguish empirically between the two scenarios, but in interpreting our estimates we view the "total" effect of $I S_{i t}^{Z}$ on the estimated $Z_{i}^{*}$ coefficient as the screening effect of interest.

To summarize, our second extension of AP's test involves using $I S_{i t}^{Z}$, which is our empirical analog to $\lambda^{z}$, to determine whether the level and slope effects of $Z_{i}^{*}$ on log-wages vary with skill importance. The model does not predict the signs of these "importance effects," but we 
conjecture that there might be a tradeoff between screening and learning: if employers can readily screen for a given skill (resulting in a relatively large $\hat{b}_{3}$ in 6 or $\hat{a}_{3 j}$ in 10), then the need to learn over time about that skill is reduced (resulting in a relatively small $\hat{b}_{5}$ in 6 or $\hat{a}_{5 j}$ in 10). ${ }^{8}$ Whether this tradeoff is more pronounced at the bottom, middle, or top of the importance distribution is an empirical question.

\section{Mobility and Labor Market Experience}

In this subsection, we consider three factors that potentially affect our ability to relate the magnitude of estimated $Z \cdot X$ coefficients in specifications 6 and 10 directly to the extent of employer learning associated with skill $Z$ : job mobility, on-the-job training, and the simple fact that we include more regressors in specifications 6 and 10 than were brought to bear in deriving expected parameter values.

Log-productivity equation 1 and log-wage specification 4 assume that $\lambda^{z}$, which represents the importance of $Z_{i}$, is constant over time and across occupations. As a result, when we derive the expected value of the estimated coefficient for $Z_{i}$ in specification 4 , the only source of timevariation in the omitted variable bias (per equation 8 ) is $S_{z g}$, which represents employer learning. In contrast to the simplified assumptions of AP's model, the marginal productivity of a given skill is expected to vary across jobs (Burdett 1978; Jovanovic 1979; Mortensen 1986). Lifecycle job mobility, therefore, introduces an additional source of time variation in the relationship between $Z_{i}$ and log-wages that cannot be distinguished from employer learning within the AP framework. If workers tend to move to jobs that place more (less) importance on a given skill than did their previous jobs, then we will over-estimate (under-estimate) employer learning. However, if workers change jobs but the relative importance of skill does not change over time in the sample, then our estimates are less likely to be affected by mobility. To assess the potential effect of mobility on our estimates, we re-estimate specifications 6 and 10 using subsamples of workers who remain in the same occupation or, alternatively, who remain in occupations placing comparable importance on a given skill. In section IV we demonstrate that, in fact, mobility does not substantially influence our estimates.

In equations 1-2, $H\left(X_{i t}\right)$ represents the fact that wages evolve over time as workers augment their pre-market skill via on-the-job training (Becker 1993; Mincer 1974). The omitted variable biases in equation 8 are derived under the assumption that this additional human capital is orthogonal to $S_{i}$ and $Z_{i}$, which ensures that its effect on log-wages is entirely captured by the experience profile when we estimate specifications 6 and 10. As noted by Farber and Gibbons (1996), if instead complementarities exist between $Z_{i}^{*}$ (the component of pre-market skill that is orthogonal to schooling) and the subsequent acquisition of productivity-enhancing human capital, then we will be unable to separate employer learning from the effects of these

\footnotetext{
${ }^{8}$ Here the term "screen" refers to the total effect of learning about a skill ex ante via its covariance with $q$ and placing an importance weight on that information.
} 
complementarities. A likely scenario is that these skill investments are complementary with $S_{i}$, which implies that $\mathrm{E}\left(b_{4}\right)>0$ in specification 6 (and $\mathrm{E}\left(a_{4}\right)>0$ in 10), in contrast to the prediction (per equation 8 ) that the $S$ - $X$ slope is zero. In section IV, we find evidence for such complementarities.

The third and final issue provides our rationale for including $R_{i}$, which represents factors other than $S_{i}$, in regression equation 7 that we use to convert raw test scores $\left(Z_{i}\right)$ to standardized, residual test scores $\left(Z_{i}^{*}\right)$. Following $\mathrm{AP}$, we derived the omitted variable biases in equations 8-9 for specification 4 , which ignores regressors other than $S_{i}$ and $Z_{i}$. When we estimate specifications 6 and 10, however, we control for additional factors, including race and ethnicity, cumulative labor market experience $\left(X_{i t}\right)$, and skill importance $\left(I S_{i t}^{Z}\right)$. In order to draw inferences based on the notion that $S_{z g}$ is the sole determinant of estimated $Z-X$ slopes (i.e., the sole determinant of $\hat{b}_{5}$ in specification 6 and $\hat{a}_{5 j}$ in specification 10), we must recognize that variances and covariances involving all remaining regressors not only affect those estimates, but can contribute (along with $S_{z g}$ ) to differences across test scores. We address this problem by using $Z_{i}^{*}$ that are orthogonal to $S_{i}, X_{i t}, I S_{i t}^{z}$, and every other regressor in 6 and $10 .^{9}$

\section{Data}

\section{A. Sample Selection}

We estimate the log-wage models described by equations 6 and 10 using data from the 1979 National Longitudinal Survey of Youth (NLSY79). We also use data on workers' attributes and job requirements from the Occupational Information Network (O*NET) to construct occupationspecific importance scores for select skills; background information on O*NET data is provided in appendix A.

The NLSY79 began in 1979 with a sample of 12,686 individuals born in 1957-1964. Sample members were interviewed annually from 1979 to 1994 and biennially from 1996 to the present. Data are currently available for 1979 through 2010, but we use data through 2000 only. ${ }^{10}$

In selecting a sample for our analysis, we adhere as closely as possible to the criteria used by AP to facilitate comparison with their study. We begin by dropping the 6,283 female NLSY79

\footnotetext{
${ }^{9}$ In equation 7 we use initial and final values of time-varying regressors, and assume that this effectively reduces their covariances with $Z_{i}$ to zero. Letting $X$ represent a single component of $R$ for illustration, once we construct residual test scores in this fashion, $S_{z x}=0$ and the expected value of $b_{5}$ is reduced to a function of $S_{z g}$ and sample moments $S_{z, Z * x}, S_{s, z * x}, S_{z, S * x}, S_{z * x, x}$, etc., as well other sample moments that do not involve $Z_{i}$ (and therefore do not vary across $Z$ ). We can use the law of iterated expectations to show that each population covariance involving $Z_{i}$ equals zero or equals a value that does not vary with $Z_{i} ;$ e.g., $S_{S, Z * x}=0$ and $S_{z, Z * x}=E(X)$. The sample moments will not be exactly zero because we have a finite and unbalanced sample, but we expect them to contribute little to cross- $Z$ variation in estimated slope parameters.

${ }^{10}$ Farber and Gibbons (1996), Altonji and Pierret (2001), Lange (2007) and Arcidiacono et al. (2010) use data through 1991, 1992, 1998 and 2004, respectively.
} 
respondents who make up roughly half the original sample. Among the 6,403 male NLS79 respondents, we drop from our sample 428 men who did not take the 10-component ASVAB test in 1980, given that we rely on these test scores to represent productivity factors that employers learn over time. We then drop 2,075 men whose initial exit from school precedes January 1978 because Census three-digit occupation codes were not systematically identified for jobs held prior to then, and we require such codes to construct occupation-specific importance scores based on $\mathrm{O}^{*} \mathrm{NET}$ data. ${ }^{11}$ We delete an additional 30 men whose reported "highest grade completed" at the time of initial school exit is less than eight. Another 799 men are deleted from the sample because we lack at least one valid wage (an average hourly wage between $\$ 1 /$ hour and \$200/hour for which a 1970 Census three-digit occupation code is available) for what the NLSY79 calls a "CPS job," which is typically the current or most recent job at the time of each interview. The relevant observation window for the selection of wages begins at initial school exit and ends at the earliest of three dates: (i) subsequent school reenrollment; (ii) the respondent's last NLSY79 interview through 2000; or (iii) 15 years after initial school exit. Of these 799 deletions, only 51 men report an otherwise-valid wage for which an occupation code is missing; most of the remaining 748 men drop out of the survey relatively soon after school exit. These selection rules leave us with a sample of 22,892 post-school wage observations contributed by 3,071 men.

As discussed in II.C, we estimate select log-wage models using subsamples of non-mobile men to determine whether our estimates are influenced by job mobility. We select observations for a subsample of "occupation stayers" by allowing each man to contribute wage observations as long as his three-digit occupation remains unchanged relative to his initial observation. We select subsamples of “importance score stayers" in a similar manner, by retaining each sample member as long as his raw skill-specific importance score does not change by more than 0.10 relative to his initial occupation's score. Each subsample has the same number of men $(3,071)$ as the full sample. The subsample of "occupation stayers" has 8,776 wage observations; sample sizes for "importance score stayers" are tied to the skill measure being used, but range from 9,666 for coding speed to 10,079 for word knowledge (see table 5B).

We also estimate select specifications for a subsample of men with exactly 12 or 16 years of schooling, and for a subsample of observations corresponding to blue collar or white collar occupations. $^{12}$ These subsamples are used for comparison with the findings of Arcidiacono et al.

\footnotetext{
${ }^{11} \mathrm{AP}$ apply a similar selection rule for the purpose of constructing an actual experience measure based on weekly employment arrays that exist for January 1978 onward. However, they relax the rule for a subset of respondents for whom weekly information can be "filled in” prior to January 1978.

${ }^{12}$ Following U.S. Census Bureau definitions, we define a wage observation as white collar if the threedigit occupation corresponds to professional, technical and kindred workers; managers and administrators, except farm; sales workers; or clerical and kindred workers. A wage observation is classified as blue collar if the three-digit occupation corresponds to craftsmen and kindred workers; operatives, except transport; transport equipment operatives; or laborers, except farm.
} 
(2010) and Bauer and Haisken-DeNew (2001) although, unlike those authors, we use pooled samples ( $S=12$ and $S=16$; blue collar and white collar) and use interactions to allow each parameter to vary by type. Our schooling sample consists of 11,944 observations for 1,461 men with 12 years of schooling and 3,312 observations for 480 men with 16 years of schooling; our occupation sample consists of 12,278 observations for 1,516 men in blue collar occupations and 6,188 observations for 953 men in white collar occupations.

\section{B. Variables}

Table 1 briefly defines the variables used to estimate our log-wage models and presents summary statistics for the full sample; appendix table B1 contains summary statistics for select subsamples described in the preceding subsection. Our dependent variable is the natural logarithm of the CPI-deflated average hourly wage, which we construct from the NLSY79 "rate of pay" variables combined with data on annual weeks worked and usual weekly hours.

For comparability across specifications, we always use a uniform set of baseline covariates. We follow convention in using highest grade completed $(S)$ as a measure of productivity that employers observe ex ante. ${ }^{13}$ Our schooling measure is based on "created" NLSY79 variables identifying the highest grade completed in May of each calendar year, and identifies the schooling level that prevails at each respondent's date of initial school exit. Because we truncate the observation period at the date of school reentry for respondents seen returning to school, our schooling measure is fixed at its pre-market level for all respondents, as required by the model; discontinuous schooling is a relatively common phenomenon among NLSY79 respondents (Light 1998, 2001) and can dramatically affect the estimates as we note in footnote 20 . We also control for potential experience $(X)$ - defined as the number of months since school exit, divided by $12-X,{ }^{2} X$, two dummy variables indicating whether the individual is black or Hispanic (with nonblack, non-Hispanic the omitted group), interactions between $S$ and the two race/ethnicity dummies and $X$, a dummy variable indicating whether the individual resides in an urban area, and individual calendar year dummies. This baseline specification mimics the one used by AP.

In a departure from prior research on employer learning (e.g., AP; Arcidiacono et al. 2010; Farber and Gibbons 1996; Lange 2007; Pinkston 2009), we control for productivity correlates that employers potentially learn over time $(Z)$ with eight alternative measures of cognitive skills. Our first measure is the one relied on throughout the existing literature: an approximate Armed Forces Qualifications Test (AFQT) score constructed from scores on four of the 10 tests that make up the Armed Services Vocational Aptitude Battery (ASVAB). ${ }^{14}$ Our remaining measures

\footnotetext{
${ }^{13}$ Highest grade completed is used to represent $S$ throughout the employer learning literature, but we suspect this measure is not directly observed by employers: resumes, job applications, and school transcripts typically report degree attainment, credit completion, and enrollment dates, but not highest grade completed. See Flores-Lagunes and Light (2010), Frazis et al. (1995) and Kane et al. (1999) for discussions of why highest grade completed and highest degree might capture distinct information.

${ }^{14} \mathrm{NLSY79}$ respondents were administered the ASVAB in 1980. All respondents were targeted for this testing — which was conducted outside the usual in-person interviews — and 94\% completed the test.
} 
are scores from seven individual components of the ASVAB: arithmetic reasoning, word knowledge, paragraph comprehension, numerical operations, coding speed, mathematical knowledge, and mechanical comprehension. We use the first four ASVAB scores because they are used to compute the AFQT score; we include the remaining scores because, along with the first four, they can be mapped with minimal ambiguity to O*NET importance scores. We provide the formula for computing AFQT scores and a mapping between ASVAB skills and O*NET measures in appendix table A1.

As detailed in section II, our use of alternative test scores presents us with a challenge not faced by analysts who rely exclusively on AFQT scores as a proxy for $Z$ : in order to compare estimated coefficients for $Z \cdot X$ and $Z$ across test scores and attribute those differences to skillspecific employer learning and screening, we have to contend with the fact that each $Z$ is correlated with $S, X$, and other regressors, and that these correlations differ across test scores. Table 2 shows correlations between each (raw) test score and $S$, black, Hispanic, $X$ and IS; because $X$ and $I S$ are time-varying, we use each worker's initial and final values. Unsurprisingly, each test score is highly correlated with $S$. These correlations range from a high of 0.644 for mathematics knowledge to a low of 0.425 for mechanical comprehension, which is arguably the most vocationally-oriented of our skill measures. Each test score is negatively correlated with black and Hispanic, and with both initial and final values of $X$-and for each variable, the degree of correlation again varies considerably across test score. ${ }^{15}$ Scores for the more academic tests (mathematics knowledge, arithmetic reasoning, work knowledge, etc.) tend to be highly correlated with skill importance, while scores for vocationally-oriented tests (coding speed, mechanical comprehension) are much less_and even negatively_correlated with importance.

To net out these correlations we regress each raw test score, using one observation per person, on each time-invariant regressor ( $S$ and the two race/ethnicity dummies) as well as initial and final values for urban status, $X, S \cdot X$, black $X$, Hispanic $X$, and the importance score corresponding to the particular test. Because NLSY79 respondents ranged in age from 16 to 23 when the ASVAB was administered, we also include birth year dummies in these regressions. We then standardize score-specific residuals to have a zero mean and standard deviation equal to one for the "one observation per person" sample of 3,071 men. As shown in table 1, the standard deviations continue to be very close to one in the regression sample consisting of 22,892 personyear observation.

Our use of alternative test scores also compels us to consider whether the seven ASVAB components measure distinct skills, or whether they simply provide alternative measures of a single, general skill. In the top panel of table 3 we demonstrate that correlation coefficients among raw scores for the seven tests range from 0.54 to 0.84 , with the largest correlations

\footnotetext{
${ }^{15}$ The pronounced, negative correlation between skill and $X_{f}$ (final potential experience) reflects the fact that less skilled individuals leave school earlier, and are therefore more likely than their more skilled counterparts to contribute an observation at (or close) to the maximum experience level of 15 years.
} 
belonging to two pairs: word knowledge and paragraph comprehension, and arithmetic reasoning and mathematics knowledge. The bottom panel of table 3 shows that most of these correlations fall to 0.30-0.50 when we use residual scores, although they remain at 0.69 for the two pairs just mentioned. Clearly, much of the correlation in the raw scores reflects the fact that sample members who are older and/or more highly-schooled tend to perform better on all tests. Once those factors are netted out, the dramatically lower correlation coefficients in the bottom panel suggest that we are not simply measuring "general skill" with seven different tests-although the skills measured by word knowledge and paragraph comprehension are undeniably similar, as are those measured by arithmetic reasoning and mathematics knowledge.

In another departure from the existing literature, our covariates include occupation-specific importance scores $\left(I S^{Z}\right)$ for each skill measure except AFQT scores. These scores, which we construct from $\mathrm{O}^{*} \mathrm{NET}$ data, represent the importance of each skill (or type of knowledge) measured by the given ASVAB component in the three-digit occupation associated with the current job (employer spell); we use the first-coded occupation for each job, so $I S^{z}$ is timeinvariant within job. For example, the score for arithmetic reasoning reflects the importance in one's occupation of being able to choose the right mathematical method to solve a problem, while the score for mathematics knowledge measures the importance of knowing arithmetic, algebra, geometry, etc. ${ }^{16}$ The "raw" importance scores range from zero to five, but we standardize all seven scores using the full sample of 22,892 person-year observations.

To substantiate that the O*NET-based measures of each skill's occupation-specification importance conform to expectations, in table 4 we present (nonstandardized) scores for six familiar occupations. Unsurprisingly, the importance scores for "word knowledge" and "paragraph comprehension" are highest for lawyers and lowest for dancers, bulldozer operators, and auto mechanics. Similarly, importance scores for "arithmetic reasoning" and "numerical operations" are highest for mathematicians and lowest for dancers. Coding speed, which is the ability to find matching numbers in a table quickly and accurately, is more important for key punch operators than for other occupations in our selected group, while mechanical knowledge is most important for auto mechanics. If any surprise is revealed by table 4, it is that basic reading, language, and mathematical skills are deemed to be fairly important in each of these disparate occupations.

\section{Findings}

Table 5A reports estimates for eight versions of specification 6, which is the standard log-wage model used by AP, Lange (2007), and others to test for employer learning. The first column of estimates uses AFQT scores to represent $Z$, the skill component that is unobserved by employers. The next seven columns replace AFQT scores with scores for individual components of the

\footnotetext{
${ }^{16}$ In appendix A we explain how O*NET creates "importance” measures and how we use O*NET data to construct our IS variables.
} 
ASVAB. In the top panel, we transform each raw test score by regressing it on birth year dummies to account for age differences when the tests were taken, and then standardize the residual scores to have unit variance. In the bottom panel-as well as in all subsequent tables in this section-we switch to the construction method described in II.B.1 and III.B in which residuals are obtained from regressions that also include $S, X$, and other covariates.

We begin by noting that the AFQT-based estimates reported in the top panel of table $5 \mathrm{~A}$ are qualitatively similar to those obtained by AP using an identical specification. ${ }^{17}$ Our estimated coefficient for $Z \cdot X(0.091)$ is larger and more precisely estimated than the estimate reported by AP (0.052), while our estimated coefficient for $S \cdot X(-0.003)$ is smaller in absolute value and equally imprecise compared to AP's estimate of -0.019. Because our AFQT-based estimated coefficients for $Z \cdot X(S \cdot X)$ are positive (negative), however, we join AP in finding support for employer learning in the presence of statistical discrimination.

When we replace AFQT scores with individual ASVAB scores in the top panel of table 5A, the estimated coefficients for $Z \cdot X$ range from 0.053 for coding speed to 0.073 for word knowledge. It is difficult to interpret these differences because, as discussed in II.B, each estimated coefficient reflects covariances between $Z$ and other regressors, including $S$; as indicated by table 2 , these covariances differ substantially across test scores. If we were to ignore these confounding covariances we would conclude that employer learning is most pronounced for word knowledge and least pronounced for coding speed and mechanical comprehension, which are the only two tests under consideration that measure vocational skill rather than general verbal and quantitative skills. This "straw man" result is surprising insofar as we might expect word knowledge to be a skill that workers can accurately signal to employers ex ante, while vocational skills would be among the skills employers learn over time by observing performance.

However, such judgments should be based on the bottom panel of table $5 \mathrm{~A}$, where we use the portion of $Z$ that is orthogonal to $S, X$, and other regressors. We can now apply the expression for $B_{3 t}$ in equation 8, which tells us that a positive estimated coefficient for $Z \cdot X$ is consistent with employer learning and that the magnitude of each estimate is a direct measure of employer learning. While each estimated $Z \cdot X$ coefficient continues to be positive in the bottom panel, we cannot reject the null hypothesis that all eight estimates are identical. Stated differently, we find evidence of employer learning for all eight skill measures, but no evidence that the degree of employer learning is skill-specific. The (statistically significant) difference seen in the top panel between the smallest estimated $Z \cdot X$ coefficient and the largest is entirely attributable to the fact that coding speed and mechanical comprehension have the smallest correlations with $S$ while word knowledge has the largest correlation (table 2). ${ }^{18}$

\footnotetext{
${ }^{17}$ As reported in their table I, column 4, AP's estimates (robust standard errors) for $Z, Z \cdot X, S$ and $S \cdot X$ are 0.022 (.042), $0.052(.034), 0.079(.015)$ and $-0.019(.012)$, respectively.

${ }^{18}$ When we construct standardized, residual test scores from regressions of $Z$ on birth year dummies and $S$ (but no additional regressors), we obtain estimates (not reported) that are virtually identical to those in the
} 
The estimates in the bottom panel of table 5A are noteworthy for two additional reasons. First, the estimated coefficients for $Z$ range from a statistically insignificant 0.007-0.012 for paragraph comprehension and word knowledge to a precisely estimated 0.034 for numerical operations. As shown by expression $B_{30}$ in equation 9 , these estimates reflect the extent to which pre-market information other than schooling is correlated with $Z\left(S_{z q}\right)$ and the importance of $\mathrm{Z}$ in determining productivity $\left(\lambda^{z}\right)$. We can conclude, therefore, that word knowledge and paragraph comprehension are either less-screenable or less important than other skills. Second, the estimated coefficients for $S \cdot X$ are small in magnitude, but uniformly positive and statistically significant. This contradicts the model's prediction (per the expression for $B_{1 t}$ in equation 8) that the relationship between $S$ and log-wages should not change with experience. As noted in II.C. (following Farber and Gibbons, 1996), a positive $S$ - $X$ slope is consistent with a feature of wage determination abstracted from in the model—viz., that highly-schooled workers invest more intensively than their less schooled counterparts in on-the-job training and/or receive a higher return to these skill investments. ${ }^{19}$

Before proceeding to a discussion of how skill importance affects our inferences, we assess the robustness of the estimates reported in the bottom panel of table 5A. Table 5B shows estimates for specification 6 based on subsamples of “occupation stayers" and "importance score stayers" described in III.A. Given that job mobility-especially toward jobs that place greater importance on the skill measured by test score $Z$ - can produce a positive estimated $Z$ - $X$ slope in the absence of employer learning, our goal is to assess the potential influence of mobility on our "full sample" estimates (table 5A) by comparing them to estimates based on subsamples of workers who do not change occupations, or who do not change occupations "enough" for the $Z$ specific importance score to change. Both sets of estimates in table $5 \mathrm{~B}$ reveal that job mobility has virtually no effect on the full sample estimates. In particular, the estimated coefficients for $Z \cdot X$ range from 0.040 to 0.053 in the "occupation stayer" subsample and from 0.041 to 0.057 in the "importance stayer" subsample (versus 0.043-0.054 in the bottom panel of table 5A). The magnitude of each estimated slope coefficient is largely invariant to whether we include mobile workers in the sample, and the finding that employer learning does not differ significantly across test scores continues to hold.

In table 5C, we present estimates for specification 6 based on a subsample of men with $S=12$ or $\mathrm{S}=16$, and a subsample of observations associated with blue collar or white collar occupations; for each subsample, we allow every parameter in the model to differ by "type.” These estimates

bottom panel of table 5A. Thus, we conclude that differences between the top- and bottom-panel estimates in table $5 \mathrm{~A}$ are due to $S_{z s}$.

${ }^{19}$ Farber and Gibbons (1996) include interactions between $S$ and year dummies in their wage model to net out secular increases in the price of skill. When we add similar interactions terms, our estimated $S \cdot X$ coefficients fall to zero or, in some cases, become negative. Because we use a narrow birth cohort and measure experience as elapsed time since school exit, we believe that skill-price effects cannot be distinguished from the effects of post-school skill acquisition. 
permit comparison with the findings of Arcidiacono et al. (2010), who identify positive $Z \cdot X$ coefficients for men with $S=12$ but not $S=16$ using the NLSY79, and Bauer and Haisken-DeNew (2001), who identify positive $Z \cdot X$ coefficients for (low-wage) blue collar but not white collar workers using German data.

The top panel of table $5 C$ reveals that estimated $Z \cdot X$ coefficients are larger for men with 12 years of schooling than for men with 16 years of schooling for each test score, but p-values for a test of equality for each score-specific pair of slope coefficients are always greater than 0.15 . This finding contrasts starkly to evidence in Arcidiacono et al. (2010), who report an imprecisely estimated $A F Q T \cdot X$ coefficient equal to $0.01-0.02$ for the $S=16$ sample, and a precisely estimated coefficient that is ten times larger for the $S=12$ sample. While they conclude that employer learning occurs only for less-schooled men, we find no evidence that employer learning differs across the two schooling groups. ${ }^{20}$

When we compare estimated $Z \cdot X$ coefficients for blue collar and white collar workers in the bottom panel of table 5C, an interesting pattern emerges: the point estimate is larger for blue collar workers than for white collar workers when we use word knowledge or mathematics knowledge, but the opposite is true when we use numerical operations, coding speed, or mechanical comprehension. Although the difference in each pair of estimates is statistically significant only for numerical operations, the pattern points to relatively more employer learning with respect to general academic skills for blue collar workers, but more employer learning with respect to vocational skills for white collar workers. This contradicts the conclusions of Bauer and Haisken-DeNew (2001), who find evidence of employer learning for low-wage, blue collar workers only. However, the two studies are not strictly comparable, given that Bauer and Haisken-DeNew use German data and a measure of parental schooling in lieu of test scores to represent $Z$.

As a group, our estimates for specification 6 reveal that employer learning exists for each skill type, for both $S=12$ and $S=16$ workers, and for both blue collar and white collar workers, but that the degree of learning does not vary across skills and worker types. In table 6 we report estimates for specification 10 , in which coefficients for $Z$ and $Z \cdot X$ are allowed to vary with skill

\footnotetext{
${ }^{20}$ Using data and programs provided by the authors (available at http://www.aeaweb.org), we determined that the findings reported by Arcidiacono et al. (2010) are driven by individuals whose $S$ varies over time. Once we eliminate individuals with time-varying $S$ from their samples, the estimated $Z \cdot X$ coefficient (S.E.) for the $S=16$ sample changes from 0.020 (.047) (as reported in column 4 of table 2 in Arcidiacono et al. 2010) to 0.103 (.050); the corresponding estimate for the $S=12$ sample changes from 0.118 (.017) to 0.109 (.019). Individuals with time-varying $S$ account for $42 \%$ of the $S=16$ sample used by Arcidiacono et al., and the majority of these men began their work lives long before reaching 16 years of schooling; e.g., they average 3.66 years of potential experience the first time they appear in the sample, versus 1.69 years for men who do not change $S$. We suspect Arcidiacono et al. (2010) find no evidence of employer learning among college-educated men because many workers in their $S=16$ sample were past the point in their careers when employer learning takes place.
} 
importance $\left(I S^{z}\right)$. As discussed in II.B, we use specification 10 to determine whether skillspecific employer learning and screening are themselves functions of the skill's importance to productivity.

In assessing the table 6 estimates, we begin by noting that the estimated coefficients for $I S^{z}$ range from 0.037 for mechanical comprehension to 0.076 for mathematics knowledge. This variable represents the skill's importance for productivity in the current three-digit occupation, and is positively correlated with $\mathrm{Z}$ for every skill but mechanical comprehension (table 2). Therefore, it is unsurprising that estimated $I S^{z}$ coefficients are positive and precisely estimated for each test score, but smaller in magnitude for mechanical comprehension than for other scores; these estimates represent a portion of each Z's effect on log-wages.

Next, we turn to the right-most columns in table 6 and observe that for mathematics knowledge and mechanical comprehension, the estimated coefficient for $Z$ increases from zero at the bottom quartile of the importance distribution to roughly 0.03 in the remaining three quartiles, while the estimated coefficient for $Z \cdot X$ decreases monotonically from a high of about 0.10 in quartile 1 to a low of about 0.02 in quartile $4 .^{21}$ As discussed in II.B.2, we cannot tell whether the positive effect of skill importance on the estimated $Z$ coefficient represents a positive effect of importance on $S_{z q}$, but we interpret this total effect as increased screening. For these two skills, therefore, we find a distinct tradeoff between screening and learning, and we find that this tradeoff varies with skill importance: when mathematics or mechanical ability is relatively unimportant to the threedigit occupation (quartile 1), employers do not screen and instead rely on performance histories to reveal over time whether workers possess the necessary skill; when mathematics or mechanical ability is relatively important to the job (quartile 4), employers rely more on screening and less on learning. We find a qualitatively similar pattern for coding speed, although for this skill the estimated coefficients for $Z$ and $Z \cdot X$ do not change as much across the $I S^{Z}$ distribution; moreover, using conventional significance levels, we fail to reject the null hypothesis that pair-wise differences among the three estimated $Z \cdot X$ coefficients equal zero.

We see evidence of tradeoffs between screening (as revealed by the estimated $Z$ coefficient) and learning (as revealed by the estimated $Z \cdot X$ coefficient) for each remaining skill in table 6 except arithmetic reasoning. For word knowledge and paragraph comprehension, employer learning increases in importance while screening decreases in importance. (As discussed in II.B.2, a finding that the estimated $Z$ coefficient decreases in importance necessarily means that $S_{z q}$ decreases in importance.) Pair-wise differences in these parameter estimates are not statistically distinguishable from zero for paragraph comprehension, but for word knowledge the estimated $Z$ coefficient decreases from a precisely estimated 0.04 when importance scores are in the bottom quartile of the distribution to zero at other points in the distribution, while the estimated $Z \cdot X$

${ }^{21}$ For each of these four triads of parameter estimates, we fail to reject the null hypothesis that the quartile 2-3 and 4 interactions are identical ( $p$-value $\geq 0.37$ ) and we reject the null that the quartile 1 interaction is identical to the other two (p-value $<0.05$ ). 
coefficient increases from an imprecisely estimated 0.03 at quartile 1 to roughly 0.06 at higher levels of importance. In short, we find a distinct screening-learning tradeoff that is the opposite of what is seen for the right-most three columns: when word knowledge is important to the job (quartile 4), employers rely on learning rather than screening. For numerical operations, it appears that screening is most pronounced and employer learning is least pronounced (i.e., the estimated $Z$ coefficient is largest and the estimated $Z \cdot X$ coefficient is smallest) when this particular skill is of "medium" importance to the three-digit occupation (i.e., $I S^{\mathrm{z}}$ falls in quartiles 2-3 of the distribution). ${ }^{22}$

\section{Conclusions}

In light of the potential centrality of employer learning to economists' understanding of lifecycle wage paths, numerous analysts have focused on the task of testing for the existence of employer learning across schooling levels (Arcidiacono et al. 2010), for blue collar and white collar workers (Bauer and Haisken-DeNew 2001), across starting occupations (Mansour 2012) and for broad samples of male workers (Altonji and Pierret 2001; Lange 2007; Pinkston 2009; Schönberg 2007). However, existing studies have relied exclusively on a single cognitive test score (AFQT scores), which means they have focused exclusively on identifying employer learning with respect to the basic language and quantitative skills measured by this test.

In the current study, we use seven cognitive test scores-each measuring a well-defined skill such as mathematical knowledge or coding speed-to determine whether employers learn more about some skills than others. We also use direct measures of skill importance to identify effects of employer screening, to determine whether tradeoffs exist between the degree of learning and screening, and to investigate the extent to which learning and screening vary with skill importance. We are able to accomplish these objectives by combining test score data from the NLSY79 with O*NET data on each skill's importance on each three-digit occupation, and by identifying conditions under which the magnitudes (and not simply the signs) of parameter estimates are directly tied to the extent of screening and employer learning.

We identify four key results. First, employer learning exists for each skill type and, within each skill type, for high school graduates, college graduates, blue collar workers, and white collar workers. Second, before the role of skill importance is brought to bear, we find little evidence that the degree of employer learning differs across skill types or worker types. Third, upon incorporating information on skill importance, we find distinct tradeoffs between employer learning and screening for several skills. Fourth, we find that the effect of skill importance on employer learning and screening differs across skills. When mathematics knowledge and

\footnotetext{
${ }^{22}$ Appendix table B3 contains estimates for a modified version of specification 10 in which we constrain the effects of $I S$ on coefficients for $Z$ and $Z \cdot X$ to be linear. For mathematics knowledge and mechanical comprehension, statistically significant estimates for the $Z \cdot I S$ and $Z \cdot X \cdot I S$ parameters capture the patterns seen in table 6 . For other skills (e.g., word knowledge and numerical operations), the restrictions serve to conceal the nonlinear patterns seen in table 6.
} 
mechanical comprehension are relatively unimportant for a given occupation, employers do not screen for these skills but instead learn about them over time; in occupations where mathematics knowledge and mechanical comprehension are relatively important, screening becomes more pronounced and employer learning less pronounced. In contrast, when word knowledge is important to occupational productivity, employer learning is pronounced and screening is nonexistent. These findings suggest that the manner in which worker ability is revealed to their employers depends intrinsically on the interplay between skill type and skill importance. Studies that focus on a single, general skill and/or explore heterogeneity in employer learning across broad types of workers have masked much of this variation.

Having developed an approach (building on Farber and Gibbons (1996)) that facilitates a comparison of how employer learning differs across skills, we conclude by suggesting two dimensions in which our analysis can be extended. First, an examination of employer learning with respect to noncognitive skills seems warranted. We have focused exclusively on cognitive skills that range from basic verbal and quantitative skills to vocationally-oriented skills. Ignoring skill importance, we conclude that employer learning does not differ across these skill types; a different conclusion might be reached if measures of conscientiousness, agreeableness, locus of control, etc. are considered. Second, existing evidence (Pinkston 2009; Schönberg 2007) that employer learning is largely public rather than private might not hold up in an analysis that considers both alternative skill types and the role of occupation-specific skill importance. 


\section{References}

Altonji, Joseph G. "Employer Learning, Statistical Discrimination and Occupational Attainment.” American Economic Review 95 (April 2005): 112-117.

Altonji, Joseph G. and Charles R. Pierret. "Employer Learning and Statistical Discrimination." Quarterly Journal of Economics 116 (February 2001): 313-50.

Arcidiacono, Peter, Patrick Bayer and Aurel Hizmo. "Beyond Signaling and Human Capital: Education and the Revelation of Ability.” American Economic Journal: Applied Economics 2 (October 2010): 76-104.

Bauer, Thomas K. and John P. Haisken-DeNew. "Employer Learning and the Returns to Schooling.” Labour Economics 8 (May 2001): 161-80.

Becker, Gary. Human Capital, $3^{\text {rd }}$ edition. Chicago: University of Chicago Press, 1993.

Burdett, Kenneth. “A Theory of Employee Search and Quits.” American Economic Review 68 (March 1978): 212-20.

Farber, Henry S. and Robert Gibbons. "Learning and Wage Dynamics.” Quarterly Journal of Economics 111 (November 1996): 1007-47.

Flores-Lagunes, Alfonso and Audrey Light. "Interpreting Degree Effects in the Returns to Education.” Journal of Human Resources 45 (Spring 2010): 439-67.

Frazis, Harley, Michelle Harrison Ports and Jay Stewart. "Comparing Measures of Educational Attainment in the CPS.” Monthly Labor Review 118 (September 1995): 40-44.

Jovanovic, Boyan. "Job Matching and the Theory of Turnover." Journal of Political Economy 87 (October 1979): 972-90.

Kane, Thomas J., Cecilia Elena Rouse, and Douglas Staiger. "Estimating Returns to Schooling When Schooling is Misreported.” NBER Working Paper No. 7235, July 1999.

Lange, Fabian. “The Speed of Employer Learning.” Journal of Labor Economics 25 (January 2007): 1-35.

Light, Audrey. "Estimating Returns to Schooling: When Does the Career Begin?" Economics of Education Review 17 (February 1998): 31-45.

Light, Audrey. "In-School Work Experience and the Returns to Schooling." Journal of Labor Economics 19 (January 2001): 65-93.

Mansour, Hani. “Does Employer Learning Vary by Occupation?” Journal of Labor Economics 30 (April 2012): 415-44.

Mincer, Jacob. Schooling, Experience, and Earnings. New York: Columbia University Press (for NBER), 1974.

Mortensen, Dale. “Job Search and Labor Market Analysis.” In Orley Ashenfelter and Richard Layard (editors), Handbook of Labor Economics, Volume 2. Amsterdam: Elsevier Science B.V., 1986.

Pinkston, Joshua C. “A Test of Screening Discrimination with Employer Learning.” Industrial and Labor Relations Review 59 (January 2006): 267-84.

Pinkston, Joshua C. "A Model of Asymmetric Employer Learning with Testable Implications." Review of Economic Studies 76 (January 2009): 367-94. 
Schonberg, Uta. “Testing for Asymmetric Learning.” Journal of Labor Economics 25 (October 2007): 651-91.

Spence, A. Michael. “Job Market Signaling.” Quarterly Journal of Economics 87 (August 1973): 355-74. 


\section{Appendix A: O*NET Data}

We use $\mathrm{O}^{*} \mathrm{NET}$ data to associate seven skill-specific importance scores (IS) with each unique job (defined as a spell with a given employer) in our NLSY79 data. These importance scores are used directly as regressors in select specifications of the log-wage model, and are used to compute the skill-specific importance-weighted experience measures (IWX) used in all specifications.

O*NET refers to the Occupational Information Network, which is a data collection and dissemination project sponsored by the Employment and Training Administration of the U.S. Department of Labor and conducted by the North Carolina Employment Security Commission. Details on the project and the data used for our analysis are available at www.onetcenter.org. O*NET replaces the Dictionary of Occupational Titles (DOT).

The O*NET database has descriptive information for 1,102 distinct occupations defined by the O*NET-SOC occupational taxonomy, which is modeled after the Standard Occupational Classification (SOC) taxonomy. The descriptive variables (referred to in O*NET documentation as “descriptors") consist of 277 distinct measures of the abilities, knowledge, skills and experience needed in the workplace as well as the tasks and activities associated with various types of work. These descriptors comprise the O*NET content model, which decomposes the various dimensions of work into three worker-oriented domains (worker characteristics, worker requirements, and experience requirements) and three job-oriented domains (occupational requirements, workforce characteristics, and occupation-specific information). Each domain contains a large set of measurable characteristics (descriptors). For example, the worker characteristics domain contains numerous measures of abilities that influence performance on the job, ranging from written comprehension to selective attention to explosive (physical) strength; it also contains measures of preferences for different work environments (artistic, social, etc.) and work styles that affect job performance (persistence, initiative, attention to detail, etc.). The worker requirements domain contains numerous types of knowledge, ranging from economics to mathematics to telecommunications, while the experience requirements domain contains measures of the amount of experience (in writing, mathematics, programming, time management, etc.) needed to enter each occupation. Some descriptors measure the importance of an ability or type of knowledge to each occupation, others measure the frequency with which a type of knowledge is used or a task is performed, while others measure the impact of decisions, amount of experience needed, etc. We focus exclusively on descriptors that identify — using a scale from one to five-the importance of select abilities and types of knowledge for each occupation.

O*NET data are updated on a "rolling" basis by conducting a survey approximately every six months that focuses on a subset of occupations in the O*NET database. Each data collection effort involves randomly sampling businesses that are likely to employ workers in the selected 
occupations, randomly sampling workers within those businesses, and then randomly assigning the sampled workers questionnaires designed to elicit occupation-specific information associated with a subset of $\mathrm{O}^{*} \mathrm{NET}$ descriptors. The data collected from surveyed workers are used to score descriptors for their occupations.

We face a number of challenges in combining O*NET data with NLSY79 data and constructing occupation-specific importance scores (IS). First, we require a reasonably clear-cut mapping between our chosen NLSY79 skill measures and the associated O*NET importance scores. Table A1 briefly describes the skill that is measured by each of the seven ASVAB scores that we use to characterize NLSY79 respondents' hard-to-observe productivity, and describes the O*NET descriptor we use to measure the skill's "importance" on the job. Using word knowledge as an example, we are measuring sample members' "ability to select the correct meaning of words presented in context," and measuring the importance in their current job of knowing "the meaning of words" as well as other language-related components. ${ }^{23}$

Second, we require uniform occupation codes in order to merge O*NET data with NLSY79 data. The O*NET database only contains O*NET-SOC codes, while for our observation period the NLSY79 provides both 1970 and 1980 3-digit Census occupation codes. We use a cross-walk to convert O*NET-SOC codes to DOT codes, and then another cross-walk to convert from DOT codes to 3-digit 1970 Census codes. In cases where multiple O*NET-SOC categories map into a given Census category, we compute the average O*NET importance score for that Census category.

Third, we need to associate each job reported in the NLSY79 with a single occupation code. In fact, longer jobs that are reported by NLSY79 respondents in multiple interviews can have timevarying occupation codes. This may reflect a "true" change in the respondent's work assignment, or it may reflect the fact that verbatim job descriptions recorded in each interview are coded differently across interview rounds. To skirt the spurious, within-job variation in occupation codes, we associate each job in the NLSY79 with the first-coded occupation; we also confirmed that using the modal or last-coded occupation does not affect our findings.

\footnotetext{
${ }^{23}$ We do not use the three remaining ASVAB scores (general science, auto/shop knowledge, electronics information) or the noncognitive skill measures available in the NLSY79 (Rotter Locus of Control, etc.) because it is much less obvious which $\mathrm{O}^{*} \mathrm{NET}$ descriptor would measure the importance of those skills on the job.
} 
Table A1: Description of NLSY79 Skill Measures and Corresponding O*NET Importance Scores

\begin{tabular}{|c|c|c|c|}
\hline NLSY79 skill measure (Z) & Description $^{\mathrm{a}}$ & O*NET score $\left(I^{Z}\right)^{Z}$ & Description $^{b}$ \\
\hline AFQT score & $\begin{array}{c}\text { Composite of } 4 \text { raw ASVAB } \\
\text { scores: } \mathrm{AR}+\mathrm{WK}+\mathrm{PC}+1 / 2 \cdot \mathrm{NO}\end{array}$ & - & - \\
\hline $\begin{array}{l}\text { Arithmetic reasoning (AR) } \\
\text { ASVAB score } 2\end{array}$ & $\begin{array}{l}\text { Ability to solve arithmetic } \\
\text { word problems. }\end{array}$ & $\begin{array}{l}\text { Mathematical } \\
\text { reasoning }^{\mathrm{c}}\end{array}$ & $\begin{array}{l}\text { Ability to choose the right mathematical } \\
\text { methods or formulas to solve a problem. }\end{array}$ \\
\hline $\begin{array}{l}\text { Word knowledge (WK) } \\
\text { ASVAB score } 3\end{array}$ & $\begin{array}{l}\text { Ability to select the correct } \\
\text { meaning of words presented } \\
\text { in context. }\end{array}$ & English language $^{\mathrm{d}}$ & $\begin{array}{l}\text { Knowledge of the structure and content } \\
\text { of the English language including the } \\
\text { meaning and spelling of words, rules of } \\
\text { composition, and grammar. }\end{array}$ \\
\hline $\begin{array}{l}\text { Paragraph comprehension (PC) } \\
\text { ASVAB score } 4\end{array}$ & $\begin{array}{l}\text { Ability to obtain information } \\
\text { from written passages. }\end{array}$ & $\begin{array}{l}\text { Written } \\
\text { comprehension }^{\mathrm{c}}\end{array}$ & $\begin{array}{l}\text { Ability to read and understand } \\
\text { information and ideas presented in } \\
\text { writing. }\end{array}$ \\
\hline $\begin{array}{l}\text { Numerical operations (NO) } \\
\text { ASVAB score } 5\end{array}$ & $\begin{array}{l}\text { Speed test of simple } \\
\text { numerical calculations. }\end{array}$ & Number facility ${ }^{\mathrm{c}}$ & $\begin{array}{l}\text { Ability to add, subtract, multiply, or } \\
\text { divide quickly and correctly. }\end{array}$ \\
\hline $\begin{array}{l}\text { Coding speed } \\
\text { ASVAB score } 6\end{array}$ & $\begin{array}{l}\text { Speed test of finding numbers } \\
\text { in a table. }\end{array}$ & Perceptual speed ${ }^{\mathrm{C}}$ & $\begin{array}{l}\text { Ability to quickly and accurately compare } \\
\text { similarities and differences among sets } \\
\text { of letters, numbers, objects, pictures, or } \\
\text { patterns. }\end{array}$ \\
\hline $\begin{array}{l}\text { Mathematics knowledge } \\
\text { ASVAB score } 8\end{array}$ & $\begin{array}{l}\text { Knowledge of high school } \\
\text { mathematics principles. }\end{array}$ & Mathematics ${ }^{\mathrm{d}}$ & $\begin{array}{l}\text { Knowledge of arithmetic, algebra, } \\
\text { geometry, calculus, statistics, and their } \\
\text { applications. }\end{array}$ \\
\hline $\begin{array}{l}\text { Mechanical comprehension } \\
\text { ASVAB score } 9\end{array}$ & $\begin{array}{l}\text { Knowledge of mechanical and } \\
\text { physical principles. }\end{array}$ & Mechanical $^{\mathrm{d}}$ & $\begin{array}{l}\text { Knowledge of machines and tools, } \\
\text { including their designs, uses, repair, and } \\
\text { maintenance. }\end{array}$ \\
\hline
\end{tabular}

${ }^{\text {a}}$ Source and NLSY79 User's Guide available at http://www.nlsinfo.org/nlsy79/docs/79html/tableofcontents.html

${ }^{\text {b} S o u r c e: ~} O^{*} N E T^{\circledR}$ Content Model: Detailed Model with Descriptions available at http://www.onetcenter.org/dl_files/ContentModel_DetailedDesc.pdf.

${ }^{\mathrm{c}}$ Ability measure from the Worker Characteristics section of the O*NET Content Model; abilities are defined as enduring attributes of the individual that influence performance.

${ }^{d}$ Knowledge measure from the Worker Requirements section of the O*NET Content Model; knowledge is defined as an organized set of principles and facts applying in general domains. 


\section{Appendix B: Supplemental Tables}

Table B1: Summary Statistics for Subsamples

\begin{tabular}{|c|c|c|c|c|c|c|c|c|c|c|}
\hline \multirow[b]{2}{*}{ Variable } & \multicolumn{2}{|c|}{ Occ. stayers } & \multicolumn{2}{|c|}{$\mathrm{S}=12$} & \multicolumn{2}{|c|}{$\mathrm{S}=16$} & \multicolumn{2}{|c|}{ Blue collar } & \multicolumn{2}{|c|}{ White collar } \\
\hline & Mean & S.D. & Mean & S.D. & Mean & S.D. & Mean & S.D. & Mean & S.D. \\
\hline Log real wage & 2.01 & .56 & 1.90 & .46 & 2.44 & .56 & 1.92 & .47 & 2.24 & .61 \\
\hline$S$ & 13.09 & 2.30 & 12.00 & 0 & 16.00 & 0 & 11.81 & 1.50 & 14.56 & 2.31 \\
\hline$X$ & 4.58 & 3.88 & 7.08 & 4.12 & 5.98 & 3.94 & 6.89 & 4.12 & 6.27 & 4.05 \\
\hline$S \cdot X / 10$ & 6.05 & 5.30 & - & - & - & - & 81.23 & 49.73 & 90.28 & 59.65 \\
\hline 1 if black & .23 & & .29 & & .15 & & .25 & & .19 & \\
\hline black $\cdot X$ & 1.08 & 2.74 & 2.17 & 4.03 & .98 & 2.79 & 1.79 & 3.73 & 1.28 & 3.16 \\
\hline 1 if Hispanic & .15 & & .15 & & .07 & & .17 & & .14 & \\
\hline Hispanic·X & .72 & 2.32 & 1.11 & 3.05 & .84 & .37 & 1.23 & 3.20 & .94 & 2.78 \\
\hline 1 if urban & .75 & & .73 & & .84 & & .72 & & .83 & \\
\hline AFQT score $^{\mathrm{a}}$ & .02 & 1.05 & .07 & 1.09 & -.01 & .73 & -.04 & 1.01 & .12 & .90 \\
\hline ASVAB scores ${ }^{a}$ & & & & & & & & & & \\
\hline Arith. reason. & .02 & .99 & .06 & 1.04 & .03 & .94 & -.01 & .98 & .05 & 1.00 \\
\hline Word know. & .00 & .96 & .06 & 1.08 & -.03 & .65 & -.01 & 1.03 & .08 & .85 \\
\hline Paragr. comp. & -.01 & .98 & .07 & 1.09 & -.04 & .68 & -.02 & 1.03 & .08 & .89 \\
\hline Numer. oper. & .03 & .99 & .08 & 1.08 & -.06 & .83 & -.02 & 1.01 & .06 & .94 \\
\hline Coding speed & .05 & .98 & .06 & 1.02 & -.04 & .94 & -.04 & .98 & .13 & .98 \\
\hline Math. know. & .02 & .99 & -.04 & 1.00 & .15 & .97 & -.04 & .93 & .16 & 1.03 \\
\hline Mech. comp. & .02 & .99 & .09 & 1.04 & -.02 & .93 & -.01 & 1.01 & .07 & .99 \\
\hline $\begin{array}{l}\text { No. obsns. } \\
\text { No. men }\end{array}$ & $\begin{array}{l}8, \\
3,\end{array}$ & & $\begin{array}{r}11,9 \\
1,46\end{array}$ & & $\begin{array}{r}3,3 \\
48\end{array}$ & & $\begin{array}{r}12,2 \\
1,51\end{array}$ & & $\begin{array}{r}6,18 \\
95\end{array}$ & \\
\hline
\end{tabular}

${ }^{\mathrm{a}}$ Summary statistics for standardized residual AFQT and ASVAB scores are reported.

Note: See table 1 and section II for additional information on subsample definitions, variable definitions, and additional covariates included in each specification. 
Table B2: Additional Estimates Corresponding to the Bottom Panel of Table 4A (Full Sample)

\begin{tabular}{|c|c|cccc|ccc|}
\hline \multirow{3}{*}{ Variable } & \multicolumn{7}{|c|}{ Skill measure used as regressor $(Z)$} \\
\cline { 2 - 8 } & AFQT & $\begin{array}{c}\text { Arith. } \\
\text { Reason. }\end{array}$ & $\begin{array}{c}\text { Word } \\
\text { Know. }\end{array}$ & $\begin{array}{c}\text { Paragr. } \\
\text { Comp. }\end{array}$ & $\begin{array}{c}\text { Numer. } \\
\text { Oper. }\end{array}$ & $\begin{array}{c}\text { Coding } \\
\text { Speed }\end{array}$ & $\begin{array}{c}\text { Math. } \\
\text { Know. }\end{array}$ & $\begin{array}{c}\text { Mech. } \\
\text { Comp. }\end{array}$ \\
\hline \multirow{2}{*}{$X^{2} / 10$} & .261 & .254 & .253 & .242 & .250 & .252 & .246 & .251 \\
& $(.081)$ & $(.081)$ & $(.081)$ & $(.081)$ & $(.080)$ & $. .081)$ & $(.081)$ & $(.081)$ \\
$X^{3} / 100$ & -.070 & -.069 & -.069 & -.068 & -.069 & -.069 & -.069 & -.068 \\
& $(.013)$ & $(.013)$ & $(.013)$ & $(.013)$ & $(.013)$ & $(.013)$ & $(.013)$ & $(.013)$ \\
black & .016 & .016 & .016 & .016 & .016 & .016 & .016 & .016 \\
& $(.006)$ & $. .006)$ & $.006)$ & $(.006)$ & $(.006)$ & $(.006)$ & $(.006)$ & $(.006)$ \\
black $\cdot X / 10$ & -.079 & -.078 & -.080 & -.078 & -.079 & -.078 & -.077 & -.079 \\
& $(.017)$ & $(.017)$ & $(.017)$ & $(.017)$ & $(.017)$ & $(.017)$ & $(.017)$ & $(.017)$ \\
Hispanic & -.013 & -.014 & -.013 & -.014 & -.014 & -.014 & -.014 & -.014 \\
& $(.002)$ & $(.002)$ & $(.002)$ & $(.002)$ & $(.002)$ & $(.002)$ & $(.002)$ & $(.002)$ \\
Hispanic $\cdot X / 10$ &. .019 & -.017 & -.018 & -.017 & -.017 & -.016 & -.018 & -.015 \\
& $(.024)$ & $(.024)$ & $(.024)$ & $(.024)$ & $(.024)$ & $(.024)$ & $(.024)$ & $(.024)$ \\
Urban & .001 & .000 & .001 & .000 & -.000 & .000 & .001 & .000 \\
& $(.003)$ & $(.003)$ & $(.003)$ & $(.003)$ & $(.003)$ & $(.003)$ & $(.003)$ & $(.003)$ \\
& .089 & .092 & .089 & .090 & .092 & .093 & .090 & .091 \\
& $(.013)$ & $(.013)$ & $(.013)$ & $(.013)$ & $(.013)$ & $(.013)$ & $(.013)$ & $(.013)$ \\
\hline
\end{tabular}

Note: The full sample consists of 22,892 observations for 3,071 men. Estimated coefficients for year dummies are not shown. Standard errors (in parentheses) are robust to clustering on individuals. 
Table B3: Estimates for Modified Model 10 Using Alternative Skill Measures (Full Sample)

\begin{tabular}{|c|c|c|c|c|c|c|c|}
\hline \multirow[b]{2}{*}{ Variable } & \multicolumn{7}{|c|}{ Skill measure used as regressor $(Z)$} \\
\hline & $\begin{array}{c}\text { Arith. } \\
\text { Reason. }\end{array}$ & $\begin{array}{c}\text { Word } \\
\text { Know. }\end{array}$ & $\begin{array}{l}\text { Paragr. } \\
\text { Comp. }\end{array}$ & $\begin{array}{l}\text { Numer. } \\
\text { Oper. }^{a}\end{array}$ & $\begin{array}{l}\text { Coding } \\
\text { Speed }\end{array}$ & $\begin{array}{l}\text { Math. } \\
\text { Know. }\end{array}$ & $\begin{array}{l}\text { Mech. } \\
\text { Comp. }\end{array}$ \\
\hline$I S^{Z}$ & $\begin{array}{c}.062 \\
(.007)\end{array}$ & $\begin{array}{c}.055 \\
(.008)\end{array}$ & $\begin{array}{c}.072 \\
(.008)\end{array}$ & $\begin{array}{c}.054 \\
(.007)\end{array}$ & $\begin{array}{c}.060 \\
(.006)\end{array}$ & $\begin{array}{c}.075 \\
(.007)\end{array}$ & $\begin{array}{c}.037 \\
(.006)\end{array}$ \\
\hline$Z$ & $\begin{array}{c}.010 \\
(.007)\end{array}$ & $\begin{array}{c}.008 \\
(.007)\end{array}$ & $\begin{array}{c}.003 \\
(.008)\end{array}$ & $\begin{array}{c}.031 \\
(.008)\end{array}$ & $\begin{array}{c}.025 \\
(.007)\end{array}$ & $\begin{array}{c}.022 \\
(.007)\end{array}$ & $\begin{array}{c}.017 \\
(.008)\end{array}$ \\
\hline$Z \cdot I S^{Z}$ & $\begin{array}{c}-.004 \\
(.007)\end{array}$ & $\begin{array}{l}-.014 \\
(.008)\end{array}$ & $\begin{array}{l}-.012 \\
(.008)\end{array}$ & $\begin{array}{l}-.013 \\
(.006)\end{array}$ & $\begin{array}{c}.004 \\
(.007)\end{array}$ & $\begin{array}{c}.011 \\
(.008)\end{array}$ & $\begin{array}{c}.015 \\
(.007)\end{array}$ \\
\hline$Z \cdot X / 10$ & $\begin{array}{c}.049 \\
(.011)\end{array}$ & $\begin{array}{c}.053 \\
(.011)\end{array}$ & $\begin{array}{l}.047 \\
(.011)\end{array}$ & $\begin{array}{c}.053 \\
(.010)\end{array}$ & $\begin{array}{c}.041 \\
(.011)\end{array}$ & $\begin{array}{c}.049 \\
(.011)\end{array}$ & $\begin{array}{c}.051 \\
(.011)\end{array}$ \\
\hline$Z \cdot X \cdot I S^{Z} / 10$ & $\begin{array}{c}-.005 \\
(.012)\end{array}$ & $\begin{array}{c}.003 \\
(.013)\end{array}$ & $\begin{array}{c}.006 \\
(.012)\end{array}$ & $\begin{array}{c}.000 \\
(.011)\end{array}$ & $\begin{array}{l}-.007 \\
(.012)\end{array}$ & $\begin{array}{l}-.025 \\
(.012)\end{array}$ & $\begin{array}{c}-.034 \\
(.011)\end{array}$ \\
\hline$S$ & $\begin{array}{c}.084 \\
(.005)\end{array}$ & $\begin{array}{c}.081 \\
(.005)\end{array}$ & $\begin{array}{c}.077 \\
(.005)\end{array}$ & $\begin{array}{c}.086 \\
(.005)\end{array}$ & $\begin{array}{c}.092 \\
(.004)\end{array}$ & $\begin{array}{c}.086 \\
(.005)\end{array}$ & $\begin{array}{c}.101 \\
(.005)\end{array}$ \\
\hline$S \cdot X / 10$ & $\begin{array}{c}.002 \\
(.001)\end{array}$ & $\begin{array}{c}.002 \\
(.001)\end{array}$ & $\begin{array}{c}.002 \\
(.001)\end{array}$ & $\begin{array}{c}.002 \\
(.001)\end{array}$ & $\begin{array}{c}.002 \\
(.001)\end{array}$ & $\begin{array}{l}.003 \\
(.001)\end{array}$ & $\begin{array}{c}.002 \\
(.001)\end{array}$ \\
\hline$X$ & $\begin{array}{c}.087 \\
(.013)\end{array}$ & $\begin{array}{c}.087 \\
(.013)\end{array}$ & $\begin{array}{c}.086 \\
(.013)\end{array}$ & $\begin{array}{c}.090 \\
(.013)\end{array}$ & $\begin{array}{c}.084 \\
(.013)\end{array}$ & $\begin{array}{c}.082 \\
(.013)\end{array}$ & $\begin{array}{c}.088 \\
(.013)\end{array}$ \\
\hline Root MSE & .447 & .449 & .448 & .445 & .447 & .444 & .449 \\
\hline
\end{tabular}

${ }^{\mathrm{a}}$ These four ASVAB scores are used to compute AFQT scores.

Note: The full sample consists of 22,892 observations for 3,071 men. All specifications include controls for $X^{2}, X^{3}$, black, Hispanic, black $X$, hispanic $X$, urban, and year dummies; the $Z$ are standardized, residual test scores. Standard errors (in parentheses) are robust to clustering on individuals. 
Table 1: Summary Statistics (full sample)

\begin{tabular}{|c|c|c|c|c|}
\hline Variable & Mean & S.D. & Mean & S.D. \\
\hline Log of CPI-deflated average hourly wage & 1.99 & .54 & \multirow{9}{*}{\multicolumn{2}{|c|}{$\frac{\text { Standardized }}{\text { scores }}$}} \\
\hline Highest grade completed (S) & 12.59 & 2.17 & & \\
\hline Years of potential experience $(\mathrm{X})^{\mathrm{a}}$ & 6.69 & 4.11 & & \\
\hline$S \cdot X / 10$ & 8.36 & 5.30 & & \\
\hline 1 if black & .26 & & & \\
\hline black $\cdot X$ & 1.79 & 3.71 & & \\
\hline 1 if Hispanic & .16 & & & \\
\hline Hispanic $\cdot \mathrm{X}$ & 1.11 & 3.04 & & \\
\hline 1 if urban & \multicolumn{2}{|c|}{ Raw scores } & & \\
\hline AFQT score (Z) & 63.83 & 22.58 & .02 & 1.08 \\
\hline ASVAB scores $(\mathrm{Z})^{\mathrm{b}}$ & & & & \\
\hline Arithmetic reasoning (AR) & 16.33 & 7.39 & .01 & .99 \\
\hline Word knowledge (WK) & 22.88 & 8.62 & .01 & 1.01 \\
\hline Paragraph comprehension (PC) & 9.45 & 3.79 & .01 & 1.01 \\
\hline Numerical operations (NO) & 30.43 & 11.25 & .01 & 1.01 \\
\hline Coding speed & 38.19 & 15.63 & .01 & 1.00 \\
\hline Mathematical knowledge & 12.18 & 6.30 & .01 & .97 \\
\hline Mechanical comprehension & 14.09 & 5.59 & .01 & 1.00 \\
\hline \multicolumn{5}{|l|}{ Importance scores $\left(I S^{Z}\right)^{\mathrm{c}}$} \\
\hline Arithmetic reasoning & 2.33 & 47 & .00 & 1.00 \\
\hline Word knowledge & 3.14 & 45 & .00 & 1.00 \\
\hline Paragraph comprehension & 3.13 & 45 & .00 & 1.00 \\
\hline Numerical operations & 2.37 & 41 & .00 & 1.00 \\
\hline Coding speed & 2.77 & 24 & .00 & 1.00 \\
\hline Mathematical knowledge & 2.91 & .41 & .00 & 1.00 \\
\hline Mechanical comprehension & 2.60 & .75 & .00 & 1.00 \\
\hline Number of observations & \multicolumn{4}{|c|}{22,892} \\
\hline
\end{tabular}

${ }^{\mathrm{a}}$ Elapsed months since first school exit, divided by 12 .

${ }^{b}$ Raw ASVAB scores reflect the number of correct answers, and the raw AFQT score equals AR+WK $+\mathrm{PC}+1 / 2 \cdot \mathrm{NO}$. Standardized AFQT and ASVAB scores are standardized residual scores; because one observation per person is used to construct and standardize the residuals, means (S.D.s) differ slightly from zero (one) in the sample of person-year observations.

${ }^{c}$ Raw scores are $\mathrm{O}^{*} \mathrm{NET}$ importance ratings (ranging from zero to five) for the three-digit occupation corresponding to each observation; see appendix A for details.

Note: All specifications also control for $Z \cdot X, \mathrm{X}^{2}, \mathrm{X}^{3}$, and calendar year dummies. 
Table 2: Pearson Correlation Coefficients for Skill Measures and Select Covariates

\begin{tabular}{|l|rrrcccc|}
\hline Skill measure & $\mathrm{S}$ & Black & Hisp. & $X_{0}$ & $X_{f}$ & $I S_{0}^{Z}$ & $I S_{f}^{Z}$ \\
\hline AFQT & .608 & -.401 & -.107 & -.063 & -.200 & - & \\
Arithmetic reasoning & .574 & -.374 & -.113 & -.079 & -.190 & .353 & .346 \\
Word knowledge & .546 & -.395 & -.091 & -.052 & -.193 & .352 & .382 \\
Paragraph comp. & .533 & -.333 & -.104 & -.047 & -.171 & .358 & .370 \\
Numerical operations & .501 & -.297 & -.071 & -.041 & -.144 & .279 & .270 \\
Coding speed & .470 & -.316 & -.038 & -.053 & -.131 & .101 & .082 \\
Math knowledge & .644 & -.303 & -.108 & -.077 & -.186 & .291 & .252 \\
Mechanical comp. & .425 & -.428 & -.095 & -.055 & -.134 & -.021 & -.058 \\
\hline
\end{tabular}

Note: Skill measures are raw (nonstandardized) scores. Potential experience $(X)$ and importance scores $\left(I S^{\mathrm{Z}}\right)$ correspond to the first and last observation for each individual. All correlation coefficients are statistically distinguishable from zero at $1 \%$ significance levels. 
Table 3: Pearson Correlation Coefficients for Skill Measures

\begin{tabular}{|c|c|c|c|c|c|c|}
\hline \multirow[b]{2}{*}{ Skill measure } & \multicolumn{6}{|c|}{ Skill measure } \\
\hline & $\begin{array}{l}\text { Word } \\
\text { Know. }\end{array}$ & $\begin{array}{l}\text { Paragr. } \\
\text { Comp. }\end{array}$ & $\begin{array}{c}\text { Numer. } \\
\text { Oper. }\end{array}$ & $\begin{array}{c}\text { Coding } \\
\text { Speed }\end{array}$ & $\begin{array}{l}\text { Math. } \\
\text { Know. }\end{array}$ & $\begin{array}{l}\text { Mech. } \\
\text { Comp. }\end{array}$ \\
\hline \multicolumn{7}{|l|}{ Raw scores } \\
\hline Arithmetic reasoning & .76 & .74 & .68 & .62 & .84 & .72 \\
\hline Word knowledge & & .83 & .65 & .62 & .72 & .72 \\
\hline Paragraph comp. & & & .64 & .61 & .70 & .68 \\
\hline Numerical operations & & & & .72 & .66 & .54 \\
\hline Coding speed & & & & & .62 & .55 \\
\hline Math knowledge & & & & & & .66 \\
\hline \multicolumn{7}{|l|}{ Residual scores } \\
\hline Arithmetic reasoning & .54 & .54 & .47 & .38 & .69 & .54 \\
\hline Word knowledge & & .69 & .43 & .39 & .47 & .54 \\
\hline Paragraph comp. & & & .42 & .39 & .47 & .31 \\
\hline Numerical operations & & & & .58 & .44 & .31 \\
\hline Coding speed & & & & & .37 & .33 \\
\hline Math knowledge & & & & & & .47 \\
\hline
\end{tabular}

Note: The top panel uses the raw (nonstandardized) scores summarized in the first columns in table 1 . The bottom panel uses standardized, residual scores summarized in the right-most columns of table 1. All scores are statistically distinguish from zero at 5\% significance levels. 
Table 4: Importance Scores for Select Occupations

\begin{tabular}{|l|l|c|c|c|c|c|c|c|}
\hline \multirow{2}{*}{} & & \multicolumn{9}{|c|}{ Importance Score } \\
\cline { 3 - 9 } Code $^{\mathrm{a}}$ & Occupation & $\begin{array}{c}\text { Arithmetic } \\
\text { reasoning }\end{array}$ & $\begin{array}{c}\text { Word } \\
\text { knowledge }\end{array}$ & $\begin{array}{c}\text { Paragraph } \\
\text { comp. }\end{array}$ & $\begin{array}{c}\text { Numerical } \\
\text { operations }\end{array}$ & $\begin{array}{c}\text { Coding } \\
\text { speed }\end{array}$ & $\begin{array}{c}\text { Mathematical } \\
\text { knowledge }\end{array}$ & $\begin{array}{c}\text { Mechanical } \\
\text { comp. }\end{array}$ \\
\hline 031 & Lawyer & 2.280 & $\mathbf{4 . 5 2 5}$ & $\mathbf{4 . 2 5 3}$ & 2.285 & 2.780 & 2.663 & 1.448 \\
035 & Mathematician & $\mathbf{3 . 8 7 5}$ & 3.875 & 3.690 & $\mathbf{3 . 5 6 5}$ & 2.690 & $\mathbf{4 . 2 6 0}$ & 1.490 \\
182 & Dancer & $\mathbf{1 . 6 3 0}$ & $\mathbf{2 . 7 8 0}$ & 3.315 & $\mathbf{1 . 7 5 5}$ & $\mathbf{2 . 6 2 5}$ & $\mathbf{1 . 6 3 0}$ & $\mathbf{1 . 2 0 0}$ \\
345 & Key punch operator & 2.630 & 3.710 & 4.250 & 2.380 & $\mathbf{3 . 7 5 0}$ & 2.950 & 1.480 \\
412 & Bulldozer operator & 1.875 & 2.880 & 2.565 & 1.815 & 2.815 & 2.940 & 3.100 \\
$\mathbf{4 7 3}$ & Auto mechanic & 2.150 & 3.127 & 3.046 & 2.216 & 2.820 & 2.959 & $\mathbf{3 . 9 6 9}$ \\
\hline
\end{tabular}

a1970 Census 3-digit occupation code.

Note: High (low) scores for each column are in bold (italics). See appendix A for details on O*NET scores. 
Table 5A: Estimates for Model 6 Using Alternative Skill Measures (Full Sample)

\begin{tabular}{|c|c|c|c|c|c|c|c|c|}
\hline \multirow[b]{2}{*}{ Variable } & \multicolumn{8}{|c|}{ Skill measure used as regressor $(Z)$} \\
\hline & AFQT & $\begin{array}{c}\text { Arith. } \\
\text { Reason. }^{\text {a }}\end{array}$ & $\begin{array}{c}\text { Word } \\
\text { Know. }^{\mathrm{a}}\end{array}$ & $\begin{array}{l}\text { Paragr. } \\
\text { Comp. }\end{array}$ & $\begin{array}{l}\text { Numer. } \\
\text { Oper. }\end{array}$ & $\begin{array}{c}\text { Coding } \\
\text { Speed } \\
\end{array}$ & $\begin{array}{l}\text { Math. } \\
\text { Know. }\end{array}$ & $\begin{array}{l}\text { Mech. } \\
\text { Comp. }\end{array}$ \\
\hline \multicolumn{9}{|c|}{$Z$ independent of birth year only ${ }^{b}$} \\
\hline$Z$ & $\begin{array}{c}.037 \\
(.010)\end{array}$ & $\begin{array}{c}.036 \\
(.009)\end{array}$ & $\begin{array}{l}.014 \\
(.009)\end{array}$ & $\begin{array}{c}.009 \\
(.010)\end{array}$ & $\begin{array}{c}.048 \\
(.009)\end{array}$ & $\begin{array}{c}.033 \\
(.009)\end{array}$ & $\begin{array}{c}.041 \\
(.010)\end{array}$ & $\begin{array}{c}.023 \\
(.009)\end{array}$ \\
\hline$Z \cdot X / 10$ & $\begin{array}{c}.091 \\
(.014)\end{array}$ & $\begin{array}{c}.063 \\
(.013)\end{array}$ & $\begin{array}{c}.073 \\
(.013)\end{array}$ & $\begin{array}{c}.064 \\
(.014)\end{array}$ & $\begin{array}{c}.065 \\
(.013)\end{array}$ & $\begin{array}{c}.053 \\
(.013)\end{array}$ & $\begin{array}{l}.066 \\
(.014)\end{array}$ & $\begin{array}{c}.054 \\
(.012)\end{array}$ \\
\hline$S$ & $\begin{array}{l}.088 \\
(.005)\end{array}$ & $\begin{array}{c}.089 \\
(.005)\end{array}$ & $\begin{array}{l}.095 \\
(.005)\end{array}$ & $\begin{array}{c}.096 \\
(.005)\end{array}$ & $\begin{array}{c}.088 \\
(.005)\end{array}$ & $\begin{array}{c}.092 \\
(.005)\end{array}$ & $\begin{array}{c}.085 \\
(.005)\end{array}$ & $\begin{array}{c}.093 \\
(.005)\end{array}$ \\
\hline$S \cdot X / 10$ & $\begin{array}{l}-.003 \\
(.008)\end{array}$ & $\begin{array}{c}.005 \\
(.008)\end{array}$ & $\begin{array}{c}.005 \\
(.008)\end{array}$ & $\begin{array}{c}.008 \\
(.007)\end{array}$ & $\begin{array}{c}.006 \\
(.007)\end{array}$ & $\begin{array}{c}.009 \\
(.007)\end{array}$ & $\begin{array}{c}.003 \\
(.008)\end{array}$ & $\begin{array}{c}.001 \\
(.007)\end{array}$ \\
\hline$X$ & .117 & .107 & .107 & .107 & .108 & .103 & .111 & .096 \\
\hline Root MSE & $\begin{array}{c}(.014) \\
.448 \\
\end{array}$ & $\begin{array}{l}(.014) \\
.445 \\
\end{array}$ & $\begin{array}{c}(.014) \\
.451\end{array}$ & $\begin{array}{c}(.014) \\
.452 \\
\end{array}$ & $\begin{array}{c}(.014) \\
.447\end{array}$ & $\begin{array}{c}(.014) \\
.451\end{array}$ & $\begin{array}{c}(.014) \\
.449 \\
\end{array}$ & $\begin{array}{c}(.013) \\
.451 \\
\end{array}$ \\
\hline \multicolumn{9}{|c|}{$\mathrm{Z}$ independent of birth year, $\mathrm{S}$, and all other covariates ${ }^{\mathrm{b}}$} \\
\hline$Z$ & $\begin{array}{c}.019 \\
(.006)\end{array}$ & $\begin{array}{c}.023 \\
(.008)\end{array}$ & $\begin{array}{c}.012 \\
(.007)\end{array}$ & $\begin{array}{c}.007 \\
(.008)\end{array}$ & $\begin{array}{c}.034 \\
(.008)\end{array}$ & $\begin{array}{c}.026 \\
(.008)\end{array}$ & $\begin{array}{l}.026 \\
(.008)\end{array}$ & $\begin{array}{l}.018 \\
(.008)\end{array}$ \\
\hline$Z \cdot X / 10$ & $\begin{array}{c}.055 \\
(.009)\end{array}$ & $\begin{array}{c}.049 \\
(.011)\end{array}$ & $\begin{array}{c}.052 \\
(.010)\end{array}$ & $\begin{array}{c}.048 \\
(.011)\end{array}$ & $\begin{array}{l}.054 \\
(.010)\end{array}$ & $\begin{array}{c}.043 \\
(.011)\end{array}$ & $\begin{array}{c}.048 \\
(.011)\end{array}$ & $\begin{array}{l}.050 \\
(.011)\end{array}$ \\
\hline$S$ & $\begin{array}{c}.097 \\
(.004)\end{array}$ & $\begin{array}{c}.097 \\
(.004)\end{array}$ & $\begin{array}{c}.097 \\
(.004)\end{array}$ & $\begin{array}{l}.097 \\
(.004)\end{array}$ & $\begin{array}{c}.097 \\
(.004)\end{array}$ & $\begin{array}{c}.097 \\
(.004)\end{array}$ & $\begin{array}{c}.097 \\
(.004)\end{array}$ & $\begin{array}{l}.097 \\
(.004)\end{array}$ \\
\hline$S \cdot X / 10$ & $\begin{array}{l}.002 \\
(.001)\end{array}$ & $\begin{array}{c}.002 \\
(.001)\end{array}$ & $\begin{array}{c}.002 \\
(.001)\end{array}$ & $\begin{array}{c}.002 \\
(.001)\end{array}$ & $\begin{array}{l}.002 \\
(.001)\end{array}$ & $\begin{array}{c}.002 \\
(.001)\end{array}$ & $\begin{array}{l}.002 \\
(.001)\end{array}$ & $\begin{array}{l}.002 \\
(.001)\end{array}$ \\
\hline$X$ & $\begin{array}{c}.094 \\
(.013)\end{array}$ & $\begin{array}{c}.092 \\
(.013)\end{array}$ & $\begin{array}{l}.092 \\
(.013)\end{array}$ & $\begin{array}{c}.093 \\
(.013)\end{array}$ & $\begin{array}{c}.093 \\
(.013)\end{array}$ & $\begin{array}{c}.092 \\
(.013)\end{array}$ & $\begin{array}{l}.090 \\
(.013)\end{array}$ & $\begin{array}{l}.090 \\
(.013)\end{array}$ \\
\hline Root MSE & .448 & .450 & .451 & .452 & .448 & .451 & .450 & .451 \\
\hline
\end{tabular}

${ }^{\mathrm{a}}$ These four ASVAB scores are used to compute AFQT scores.

${ }^{\mathrm{b}}$ In the bottom panel, all $Z$ are standardized, residual test scores obtained by regressing each test score on birth year dummies and starting/ending values of all covariates (including IS), as detailed in section III.B. In the top panel, we use standardized, residual test scores obtained by regressing each test score on birth year dummies only.

Note: The full sample consists of 22,892 observations for 3,071 men. All specifications include controls for $X^{2}, X^{3}$, black, Hispanic, black $X$, hispanic $X$, urban, and year dummies; see table B2 for additional parameter estimates corresponding to the bottom panel. Standard errors (in parentheses) are robust to clustering on individuals. 
Table 5B: Estimates for Model 6 Using Alternative Skill Measures

(Subsamples of occupation stayers and importance score stayers)

\begin{tabular}{|c|c|c|c|c|c|c|c|c|}
\hline \multirow[b]{2}{*}{ Variable } & \multicolumn{8}{|c|}{ Skill measure used as regressor $(Z)$} \\
\hline & AFQT & $\begin{array}{c}\text { Arith. } \\
\text { Reason. }\end{array}$ & $\begin{array}{c}\text { Word } \\
\text { Know. }\end{array}$ & $\begin{array}{l}\text { Paragr. } \\
\text { Comp. }\end{array}$ & $\begin{array}{l}\text { Numer. } \\
\text { Oper. }{ }^{a}\end{array}$ & $\begin{array}{l}\text { Coding } \\
\text { Speed }\end{array}$ & $\begin{array}{l}\text { Math. } \\
\text { Know. }\end{array}$ & $\begin{array}{l}\text { Mech. } \\
\text { Comp. }\end{array}$ \\
\hline \multicolumn{9}{|l|}{ Occupation } \\
\hline$Z$ & $\begin{array}{c}.012 \\
(.008)\end{array}$ & $\begin{array}{c}.017 \\
(.008)\end{array}$ & $\begin{array}{c}.002 \\
(.009)\end{array}$ & $\begin{array}{c}.002 \\
(.009)\end{array}$ & $\begin{array}{c}.030 \\
(.009)\end{array}$ & $\begin{array}{c}.019 \\
(.009)\end{array}$ & $\begin{array}{c}.025 \\
(.009)\end{array}$ & $\begin{array}{c}.007 \\
(.009)\end{array}$ \\
\hline$Z \cdot X / 10$ & $\begin{array}{c}.053 \\
(.021)\end{array}$ & $\begin{array}{c}.053 \\
(.023)\end{array}$ & $\begin{array}{c}.044 \\
(.027)\end{array}$ & $\begin{array}{c}.040 \\
(.024)\end{array}$ & $\begin{array}{c}.047 \\
(.022)\end{array}$ & $\begin{array}{c}.041 \\
(.021)\end{array}$ & $\begin{array}{c}.046 \\
(.023)\end{array}$ & $\begin{array}{c}.043 \\
(.024)\end{array}$ \\
\hline$S$ & $\begin{array}{c}.093 \\
(.005)\end{array}$ & $\begin{array}{c}.094 \\
(.005)\end{array}$ & $\begin{array}{c}.093 \\
(.005)\end{array}$ & $\begin{array}{c}.094 \\
(.005)\end{array}$ & $\begin{array}{c}.093 \\
(.005)\end{array}$ & $\begin{array}{c}.092 \\
(.005)\end{array}$ & $\begin{array}{c}.094 \\
(.005)\end{array}$ & $\begin{array}{c}.093 \\
(.005)\end{array}$ \\
\hline$S \cdot X / 10$ & $\begin{array}{c}.003 \\
(.001)\end{array}$ & $\begin{array}{c}.003 \\
(.001)\end{array}$ & $\begin{array}{c}.003 \\
(.001)\end{array}$ & $\begin{array}{c}.003 \\
(.001)\end{array}$ & $\begin{array}{c}.004 \\
(.001)\end{array}$ & $\begin{array}{c}.003 \\
(.001)\end{array}$ & $\begin{array}{c}.003 \\
(.001)\end{array}$ & $\begin{array}{c}.003 \\
(.001)\end{array}$ \\
\hline$X$ & $\begin{array}{c}.107 \\
(.022)\end{array}$ & $\begin{array}{c}.109 \\
(.022)\end{array}$ & $\begin{array}{l}.106 \\
(.022)\end{array}$ & $\begin{array}{l}.107 \\
(.022)\end{array}$ & $\begin{array}{l}.102 \\
(.021)\end{array}$ & $\begin{array}{l}.102 \\
(.022)\end{array}$ & $\begin{array}{l}.111 \\
(.022)\end{array}$ & $\begin{array}{l}.106 \\
(.022)\end{array}$ \\
\hline Root MSE & .443 & .443 & .445 & .447 & .442 & .444 & .443 & .444 \\
\hline Import. Score & & & & & & & & \\
\hline & & $\begin{array}{c}.019 \\
(.009)\end{array}$ & $\begin{array}{c}.004 \\
(.008)\end{array}$ & $\begin{array}{c}.001 \\
(.009)\end{array}$ & $\begin{array}{c}.031 \\
(.009)\end{array}$ & $\begin{array}{c}.019 \\
(.009)\end{array}$ & $\begin{array}{c}.026 \\
(.009)\end{array}$ & $\begin{array}{c}.010 \\
(.009)\end{array}$ \\
\hline$Z \cdot X / 10$ & & $\begin{array}{c}.057 \\
(.020)\end{array}$ & $\begin{array}{c}.048 \\
(.022)\end{array}$ & $\begin{array}{c}.049 \\
(.020)\end{array}$ & $\begin{array}{l}.048 \\
(.019)\end{array}$ & $\begin{array}{c}.041 \\
(.019)\end{array}$ & $\begin{array}{c}.042 \\
(.021)\end{array}$ & $\begin{array}{c}.047 \\
(.020)\end{array}$ \\
\hline$S$ & & $\begin{array}{c}.093 \\
(.005)\end{array}$ & $\begin{array}{c}.095 \\
(.005)\end{array}$ & $\begin{array}{c}.094 \\
(.005)\end{array}$ & $\begin{array}{c}.091 \\
(.005)\end{array}$ & $\begin{array}{c}.093 \\
(.005)\end{array}$ & $\begin{array}{c}.095 \\
(.005)\end{array}$ & $\begin{array}{c}.094 \\
(.005)\end{array}$ \\
\hline$S \cdot X / 10$ & & $\begin{array}{c}.003 \\
(.001)\end{array}$ & $\begin{array}{c}.003 \\
(.001)\end{array}$ & $\begin{array}{c}.003 \\
(.001)\end{array}$ & $\begin{array}{c}.004 \\
(.001)\end{array}$ & $\begin{array}{c}.003 \\
(.001)\end{array}$ & $\begin{array}{c}.004 \\
(.001)\end{array}$ & $\begin{array}{c}.002 \\
(.001)\end{array}$ \\
\hline$X$ & & $\begin{array}{l}.105 \\
(.020)\end{array}$ & $\begin{array}{l}.118 \\
(.019)\end{array}$ & $\begin{array}{c}.101 \\
(.020)\end{array}$ & $\begin{array}{c}.094 \\
(.020)\end{array}$ & $\begin{array}{c}.099 \\
(.020)\end{array}$ & $\begin{array}{l}.101 \\
(.020)\end{array}$ & $\begin{array}{c}.119 \\
(.019)\end{array}$ \\
\hline Root MS & & .445 & .446 & .442 & .446 & .442 & .444 & .443 \\
\hline Observations & & 9,972 & 10,079 & 9,922 & 9,933 & 9,666 & 9,948 & 10,073 \\
\hline
\end{tabular}

${ }^{\mathrm{a}}$ These four ASVAB scores are used to compute AFQT scores.

The subsample of occupation stayers consists of 8,776 observations for the 3,071 men in the full sample; each man contributes observations as long as he maintains his initial three-digit occupation. Each subsample of importance score stayers consists of observations for the 3,071 men in the full sample; each man contributes observations as long as his skill-specific importance score varies less than 0.1 relative to his initial score, so sample sizes are skill-specific. All specifications include controls for $X^{2}, X^{3}$, black, Hispanic, black $X$, hispanic $X$, urban, and year dummies; the $Z$ are standardized residual test scores. Standard errors (in parentheses) are robust to clustering on individuals. 
Table 5C: Estimates for Model 6 Using Alternative Skill Measures

(Subsamples of men with schooling=12 or 16, and men in blue or white collar occupations)

\begin{tabular}{|c|c|c|c|c|c|c|c|c|}
\hline \multirow[b]{2}{*}{ Variable } & \multicolumn{8}{|c|}{ Skill measure used as regressor $(Z)$} \\
\hline & AFQT & $\begin{array}{l}\text { Arith. } \\
\text { Reason. }\end{array}$ & $\begin{array}{l}\text { Word } \\
\text { Know. }^{\text {a }}\end{array}$ & $\begin{array}{l}\text { Paragr. } \\
\text { Comp. }^{\text {a }}\end{array}$ & $\begin{array}{l}\text { Numer. } \\
\text { Oper. }\end{array}$ & $\begin{array}{c}\text { Coding } \\
\text { Speed }\end{array}$ & $\begin{array}{l}\text { Math. } \\
\text { Know. }\end{array}$ & $\begin{array}{l}\text { Mech. } \\
\text { Comp. }\end{array}$ \\
\hline \multicolumn{9}{|l|}{ Schooling $=12$} \\
\hline \multirow[t]{2}{*}{ Z } & .026 & .019 & .015 & .014 & .046 & .038 & .021 & .010 \\
\hline & $(.010)$ & $(.010)$ & $(.010)$ & $(.011)$ & $(.010)$ & $(.011)$ & $(.010)$ & $(.010)$ \\
\hline \multirow[t]{2}{*}{$Z \cdot X / 10$} & .067 & .054 & .060 & .047 & .053 & .047 & .054 & .058 \\
\hline & $(.013)$ & $(.013)$ & $(.012)$ & $(.013)$ & $(.013)$ & $(.014)$ & $(.013)$ & $(.014)$ \\
\hline \multicolumn{9}{|l|}{ Schooling $=16$} \\
\hline \multirow[t]{2}{*}{$Z$} & .022 & .038 & -.013 & -.018 & .026 & .028 & $.054^{*}$ & .036 \\
\hline & $(.025)$ & $(.018)$ & $(.030)$ & $(.028)$ & $(.025)$ & $(.019)$ & $(.019)$ & $(.019)$ \\
\hline \multirow[t]{2}{*}{$Z \cdot X / 10$} & .055 & .033 & .012 & .024 & .046 & .023 & .038 & .020 \\
\hline & $(.036)$ & $(.026)$ & $(.045)$ & $(.046)$ & $(.035)$ & $(.038)$ & $(.026)$ & $(.031)$ \\
\hline Root MSE & .448 & .450 & .450 & .452 & .446 & .449 & .449 & .451 \\
\hline \multicolumn{9}{|l|}{ Blue collar } \\
\hline \multirow[t]{2}{*}{ Z } & .026 & .025 & .012 & .005 & .046 & .031 & .025 & .018 \\
\hline & $(.010)$ & $(.010)$ & $(.010)$ & $(.011)$ & $(.010)$ & $(.011)$ & $(.010)$ & $(.010)$ \\
\hline \multirow[t]{2}{*}{$Z \cdot X / 10$} & .054 & .042 & .051 & .045 & .030 & .021 & .044 & .038 \\
\hline & $(.013)$ & $(.014)$ & $(.012)$ & $(.013)$ & $(.013)$ & $(.014)$ & $(.014)$ & $(.013)$ \\
\hline \multirow[t]{2}{*}{$S$} & .080 & .082 & .081 & .082 & .079 & .081 & .082 & .081 \\
\hline & $(.007)$ & $(.007)$ & $(.007)$ & $(.007)$ & $(.007)$ & $(.007)$ & $(.007)$ & $(.007)$ \\
\hline \multirow[t]{2}{*}{$S \cdot X / 10$} & .000 & .003 & .001 & .000 & .001 & .003 & .009 & .004 \\
\hline & $(.010)$ & $(.010)$ & $(.010)$ & $(.010)$ & $(.010)$ & $(.010)$ & $(.009)$ & $(.010)$ \\
\hline \multicolumn{9}{|l|}{ White collar } \\
\hline \multirow[t]{2}{*}{$Z$} & .038 & .026 & .028 & $.035^{*}$ & .035 & .037 & .047 & .039 \\
\hline & $(.015)$ & $(.014)$ & $(.016)$ & $(.017)$ & $(.016)$ & $(.014)$ & $(.013)$ & $(.015)$ \\
\hline \multirow[t]{2}{*}{$Z \cdot X / 10$} & .077 & .042 & .039 & .046 & $.076^{* *}$ & .042 & .030 & .042 \\
\hline & $(.026)$ & $(.014)$ & $(.028)$ & $(.026)$ & $(.025)$ & $(.025)$ & $(.022)$ & $(.024)$ \\
\hline$S$ & $\begin{array}{l}.113^{* * *} \\
(.009)\end{array}$ & $\begin{array}{l}.111^{* * *} \\
(.009)\end{array}$ & $\begin{array}{l}.113^{* * *} \\
(.008)\end{array}$ & $\begin{array}{l}.114^{* * *} \\
(.008)\end{array}$ & $\begin{array}{l}.111^{* * *} \\
(.009)\end{array}$ & $\begin{array}{l}.112^{* * *} \\
(.009)\end{array}$ & $\begin{array}{l}.111^{* * *} \\
(.008)\end{array}$ & $\begin{array}{l}.112^{* * *} \\
(.009)\end{array}$ \\
\hline \multirow[t]{2}{*}{$S \cdot X / 10$} & .022 & .020 & .019 & .019 & $.024^{*}$ & .022 & .020 & .022 \\
\hline & $(.001)$ & $(.013)$ & $(.013)$ & $(.013)$ & $(.012)$ & $(.013)$ & $(.013)$ & $(.013)$ \\
\hline Root MSE & .446 & .448 & .449 & .449 & .446 & .449 & .448 & .448 \\
\hline
\end{tabular}

${ }^{\text {a}}$ These four ASVAB scores are used to compute AFQT scores.

${ }^{*},{ }^{* *}$, and ${ }^{* * *}$ indicate that the $\mathrm{p}$-value for the null hypothesis that the two parameters are equal across types ( $S=12$ and $S=16$, or blue and white collar) is less than or equal to $0.15,0.10$, and 0.01 .

Note: The schooling subsample consists of 11,944 observations for 1,461 men with $S=12$ and 3,312 observations for 480 men with $S=16$; the occupation subsample consists of 12,278 observations for 1,516 men in blue collar occupations and 6,188 observations for 953 men in white collar occupations. All specifications include the full set of controls described in table 5A (with $\mathrm{S}$ and $\mathrm{S} \cdot \mathrm{X}$ dropped from the schooling sample) fully interacted with dummies indicating $S$-level or blue/white collar status; the $Z$ are standardized, residual test scores. Standard errors (in parentheses) are robust to clustering on individuals. 
Table 6: Estimates for Model 10 Using Alternative Skill Measures (Full Sample)

\begin{tabular}{|c|c|c|c|c|c|c|c|}
\hline \multirow[b]{2}{*}{ Variable } & \multicolumn{7}{|c|}{ Skill measure used as regressor $(Z)$} \\
\hline & $\begin{array}{c}\text { Arith. } \\
\text { Reason. }\end{array}$ & $\begin{array}{c}\text { Word } \\
\text { Know. }^{\text {a }}\end{array}$ & $\begin{array}{l}\text { Paragr. } \\
\text { Comp. }^{\text {a }}\end{array}$ & $\begin{array}{l}\text { Numer. } \\
\text { Oper. }{ }^{a}\end{array}$ & $\begin{array}{c}\text { Coding } \\
\text { Speed }\end{array}$ & $\begin{array}{l}\text { Math. } \\
\text { Know. }\end{array}$ & $\begin{array}{l}\text { Mech. } \\
\text { Comp. }\end{array}$ \\
\hline$I S^{Z}$ & $\begin{array}{c}.063 \\
(.007)\end{array}$ & $\begin{array}{c}.055 \\
(.008)\end{array}$ & $\begin{array}{c}.072 \\
(.008)\end{array}$ & $\begin{array}{c}.055 \\
(.007)\end{array}$ & $\begin{array}{c}.060 \\
(.006)\end{array}$ & $\begin{array}{c}.076 \\
(.007)\end{array}$ & $\begin{array}{c}.036 \\
(.006)\end{array}$ \\
\hline a. $\left.Z\right|_{\mathrm{Q} 1 \text { IS }}$ & $\begin{array}{c}.019 \\
(.014)\end{array}$ & $\begin{array}{c}.040 \\
(.013)\end{array}$ & $\begin{array}{c}.015 \\
(.015)\end{array}$ & $\begin{array}{c}.033 \\
(.014)\end{array}$ & $\begin{array}{c}.029 \\
(.013)\end{array}$ & $\begin{array}{l}-.003 \\
(.015)\end{array}$ & $\begin{array}{l}-.013 \\
(.014)\end{array}$ \\
\hline b. $\left.Z\right|_{\text {Q2-Q3 IS }}$ & $\begin{array}{c}.026 \\
(.010)\end{array}$ & $\begin{array}{c}.002 \\
(.010)\end{array}$ & $\begin{array}{c}.004 \\
(.010)\end{array}$ & $\begin{array}{c}.054 \\
(.010)\end{array}$ & $\begin{array}{c}.011 \\
(.011)\end{array}$ & $\begin{array}{c}.034 \\
(.010)\end{array}$ & $\begin{array}{c}.027 \\
(.011)\end{array}$ \\
\hline c. $\left.Z\right|_{\mathrm{Q} 4 \text { IS }}$ & $\begin{array}{c}.009 \\
(.015)\end{array}$ & $\begin{array}{c}-.009 \\
(.018)\end{array}$ & $\begin{array}{l}-.007 \\
(.020)\end{array}$ & $\begin{array}{c}-.018 \\
(.017)\end{array}$ & $\begin{array}{c}.047 \\
(.016)\end{array}$ & $\begin{array}{c}.025 \\
(.016)\end{array}$ & $\begin{array}{c}.030 \\
(.015)\end{array}$ \\
\hline d. $Z \cdot X /\left.10\right|_{\mathrm{Q} 1}$ IS & $\begin{array}{l}.050 \\
(.022)\end{array}$ & $\begin{array}{l}.028 \\
(.018)\end{array}$ & $\begin{array}{c}.037 \\
(.019)\end{array}$ & $\begin{array}{c}.070 \\
(.018)\end{array}$ & $\begin{array}{c}.051 \\
(.023)\end{array}$ & $\begin{array}{c}.096 \\
(.023)\end{array}$ & $\begin{array}{l}.105 \\
(.024)\end{array}$ \\
\hline e. $Z \cdot X /\left.10\right|_{\mathrm{Q} 2-\mathrm{Q} 3}$ IS & $\begin{array}{c}.057 \\
(.014)\end{array}$ & $\begin{array}{c}.062 \\
(.013)\end{array}$ & $\begin{array}{c}.046 \\
(.014)\end{array}$ & $\begin{array}{c}.032 \\
(.013)\end{array}$ & $\begin{array}{c}.047 \\
(.014)\end{array}$ & $\begin{array}{c}.041 \\
(.014)\end{array}$ & $\begin{array}{c}.036 \\
(.016)\end{array}$ \\
\hline f. $Z \cdot X /\left.10\right|_{\mathrm{Q} 4} I S$ & $\begin{array}{c}.025 \\
(.023)\end{array}$ & $\begin{array}{c}.059 \\
(.031)\end{array}$ & $\begin{array}{c}.058 \\
(.029)\end{array}$ & $\begin{array}{c}.079 \\
(.025)\end{array}$ & $\begin{array}{c}.024 \\
(.025)\end{array}$ & $\begin{array}{c}.018 \\
(.022)\end{array}$ & $\begin{array}{c}.021 \\
(.018)\end{array}$ \\
\hline$S$ & $\begin{array}{l}.084 \\
(.005)\end{array}$ & $\begin{array}{c}.081 \\
(.005)\end{array}$ & $\begin{array}{c}.078 \\
(.005)\end{array}$ & $\begin{array}{c}.086 \\
(.005)\end{array}$ & $\begin{array}{c}.093 \\
(.004)\end{array}$ & $\begin{array}{c}.086 \\
(.005)\end{array}$ & $\begin{array}{c}.101 \\
(.004)\end{array}$ \\
\hline$S \cdot X / 10$ & $\begin{array}{c}.002 \\
(.001)\end{array}$ & $\begin{array}{c}.002 \\
(.001)\end{array}$ & $\begin{array}{c}.002 \\
(.001)\end{array}$ & $\begin{array}{c}.002 \\
(.001)\end{array}$ & $\begin{array}{c}.002 \\
(.001)\end{array}$ & $\begin{array}{c}.002 \\
(.001)\end{array}$ & $\begin{array}{c}.002 \\
(.001)\end{array}$ \\
\hline$X$ & $\begin{array}{l}.087 \\
(.013)\end{array}$ & $\begin{array}{c}.087 \\
(.013)\end{array}$ & $\begin{array}{l}.086 \\
(.013)\end{array}$ & $\begin{array}{c}.090 \\
(.013)\end{array}$ & $\begin{array}{c}.084 \\
(.013)\end{array}$ & $\begin{array}{c}.082 \\
(.013)\end{array}$ & $\begin{array}{c}.087 \\
(.013)\end{array}$ \\
\hline Root MSE & .447 & .449 & .448 & .445 & .447 & .444 & .449 \\
\hline P-values ${ }^{b}$ & & & & & & & \\
\hline $\begin{array}{l}\text { row a.-D. } \\
\text { row b.-c. }\end{array}$ & $\begin{array}{l}.69 \\
.35\end{array}$ & $\begin{array}{l}.02 \\
.60\end{array}$ & $\begin{array}{l}.56 \\
.63\end{array}$ & $\begin{array}{l}.22 \\
.00\end{array}$ & $\begin{array}{l}.26 \\
.06\end{array}$ & $\begin{array}{l}.04 \\
.66\end{array}$ & $\begin{array}{l}.02 \\
.87\end{array}$ \\
\hline row a.-c. & .63 & .03 & .39 & .02 & .38 & .17 & .03 \\
\hline row d.-e. & .79 & .14 & .69 & .09 & .90 & .04 & .01 \\
\hline row e.-f. & .22 & .95 & .70 & .09 & .18 & .37 & .52 \\
\hline row d.-f. & .41 & .38 & .52 & .78 & .19 & .02 & .00 \\
\hline
\end{tabular}

${ }^{\mathrm{a}}$ These four ASVAB scores are used to compute AFQT scores.

${ }^{\mathrm{b}} \mathrm{P}$-values for tests of the null hypothesis that the difference between the two parameter estimates identified by row labels is zero.

Note: The full sample consists of 22,892 observations for 3,071 men. All specifications include controls for $X^{2}, X^{3}$, black, Hispanic, black $X$, hispanic $\cdot X$, urban, and year dummies; the $Z$ are standardized, residual test scores. Standard errors (in parentheses) are robust to clustering on individuals. 